\title{
تأثير المعلوماتية على المراكز التجارية في المدينة
}

م.: أحمد حلمي محمد عبد الله - أ.د.: غادة فاروق حسن - أ.د.: أحمد سامي عبد الرحمن

الملخص:

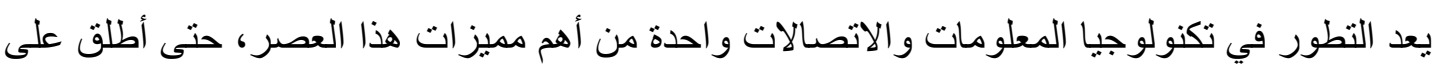

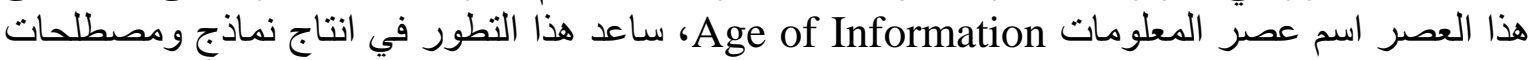

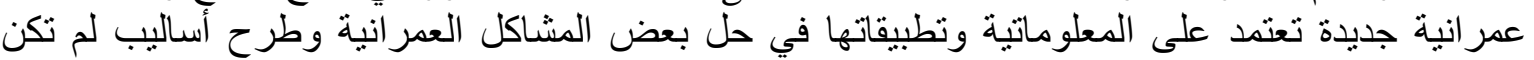

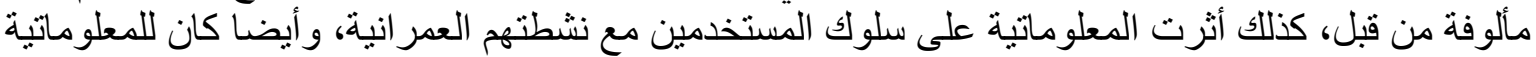

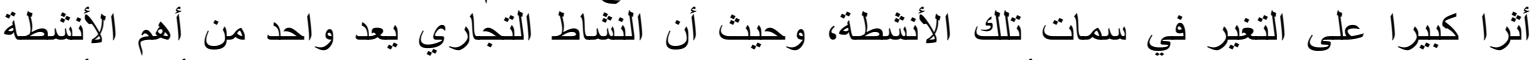

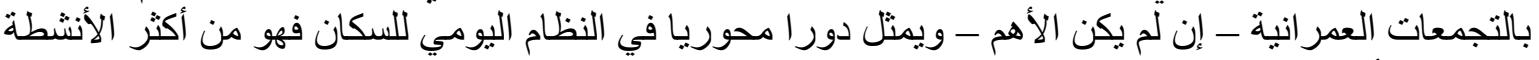

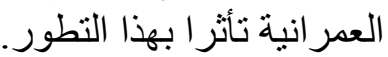

Information and لذلك يهتم هذا البحث برصد تأثير التطور في تكنولوجيا المعلومات والاتصالات Telecommunication Technologies (ICT)

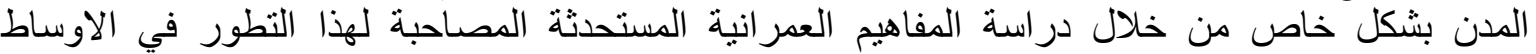

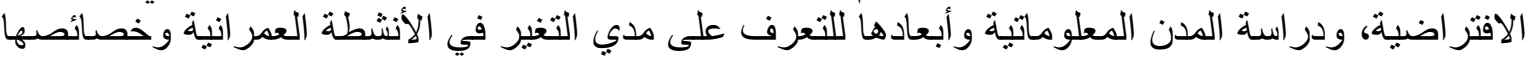

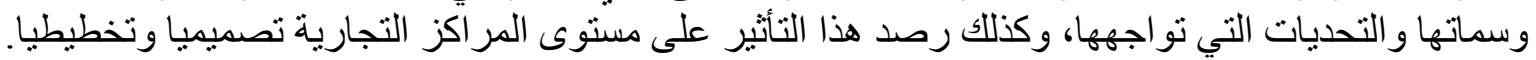

الكلمات المفتاحية: ICT، عصر المعلومات، المر اكز التجارية، المعلوماتية

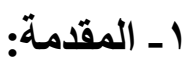

شهد العـالم خلال العقد الأخير تطور هائل في كافة الانشطة والعلوم بالمقارنـة مع العصدور السـابقة،

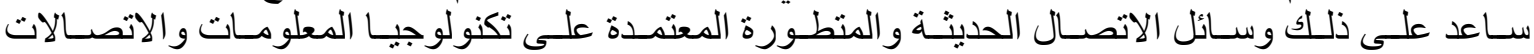
Information and Telecommunication Technologies (ICT) نتيجة لتطور الكبير في مجال صناعة الالكترونيات و المعالجات المستخدمة في الحو اسيب وأجهزة الاتصات ونسال

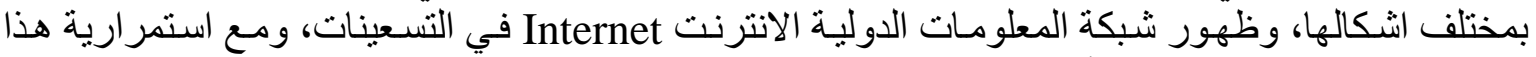

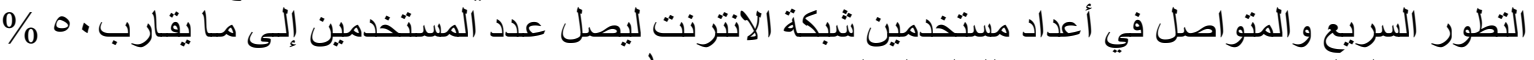

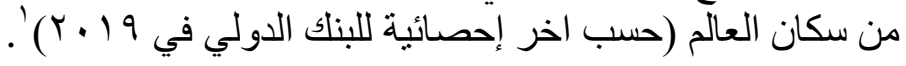

نتيجة الي ذلك التطور الهائل في تكنولوجيا المعلومات والاتصالات (ICT)، كان لذلك بـالغ التأثير على شكل التهل

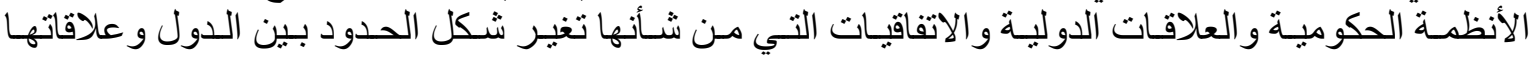

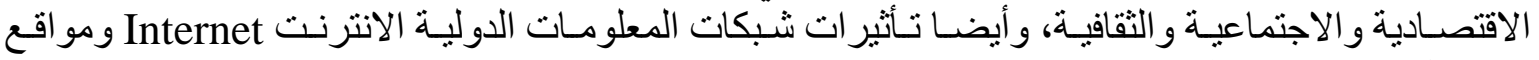

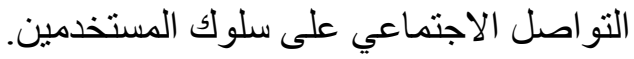

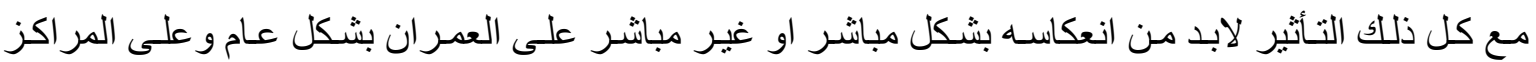

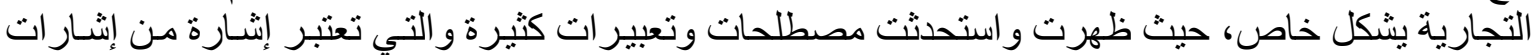

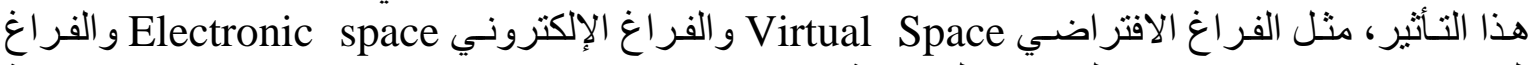

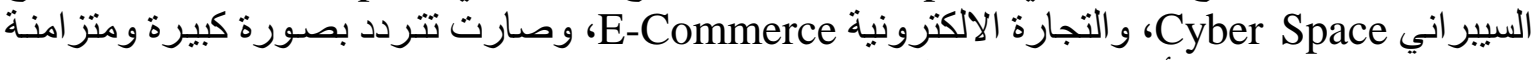

مع التطور المستمر لكافة أمور الحياة. ويقول المعماري الياباني Kenzo Tange:

\footnotetext{
${ }^{1}$ Organization Website - World Bank - https://data.worldbank.org/indicator/it.net.user.zs, 2021.
} 
"Technological considerations are of great importance to architecture and cities in the informational society ${ }^{2,}$

$$
\text { 2ـ إإن للاعتبار ات التكنولوجية بالغ الأهمية على العمارة و العمر ان في المجتمعات المعلوماتية". }
$$

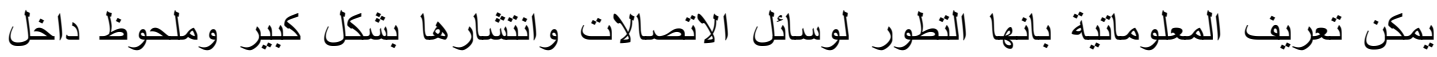

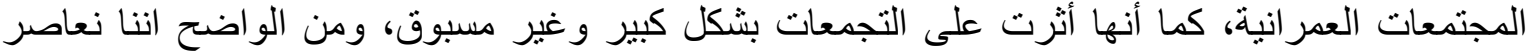

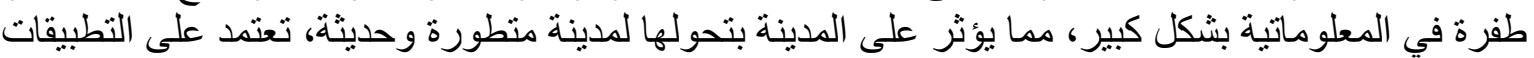

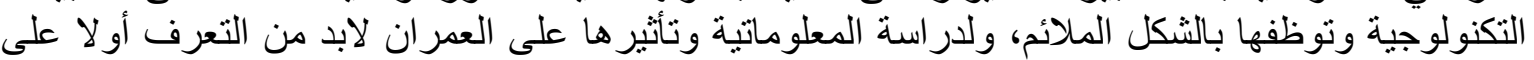
انماط الأوساط الافتر اضية المستحدثة و انماط المدن المستقبلية المتأثرة بالمعلية على ماتية:

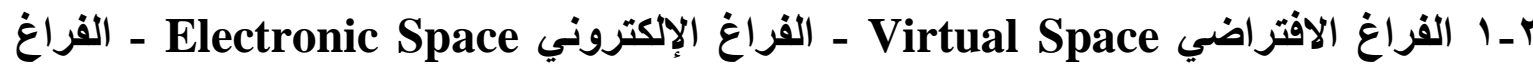

السيبراني Cyber Space

هو عبارة عن بيئة رقمية يتفاعل فيها الافراد والجماعات وحتى المنظمات في مساحات غير مادية (افتراضية)، يمكن ظهوره في صور مختلفة لتلائم النشاط الذي يؤديه (فصل افتراضي، فئ مركز تجاري

افتر اضي، متحف افتر اضي ....الخ).

\section{r Y r r الواقع الأفتراضي Virtual Reality (VR)}

هو عبارة عن محاكاة Simulation للبيئات التي يمكن محاكاتها مادياً في بعض الأمساكن في العـالم الحقيقي عن طريق الحاسوب، وذللك في العوالم الافتر اضية (غير المادية).

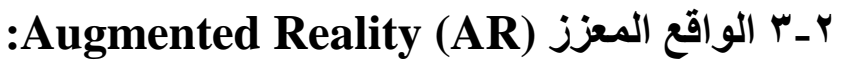

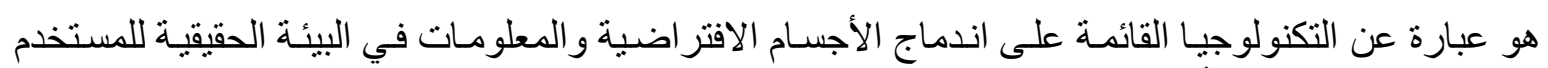

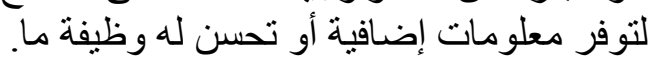

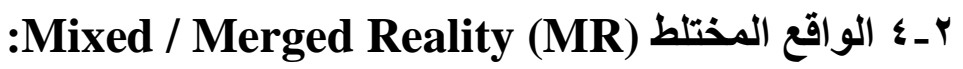

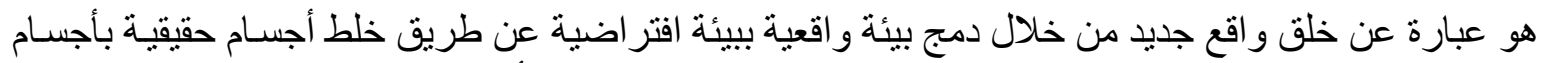

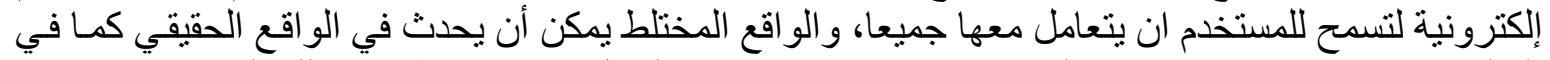

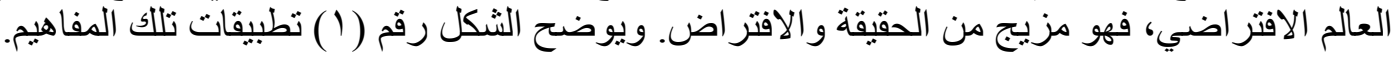

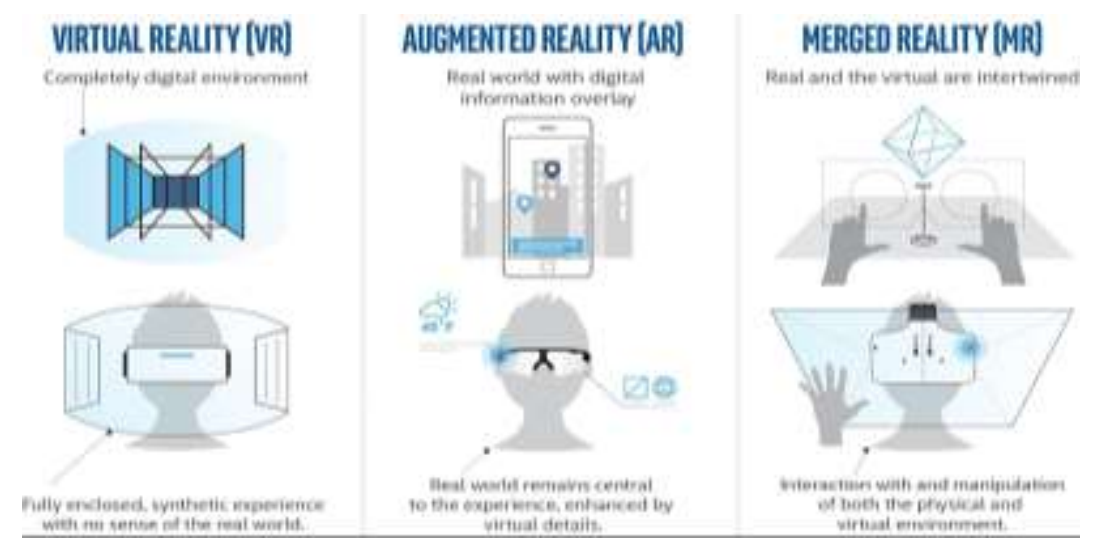

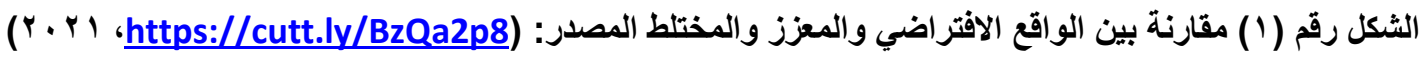

\footnotetext{
${ }^{2}$ Riewoldt, O., Intelligent Spaces, Architecture for The Information Age, Laurence king, Hong Kong, 1997.
} 


\section{r Technological City المدينة التكنولوجية}

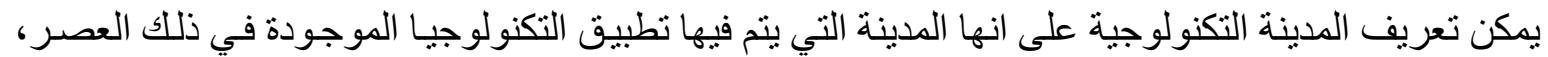

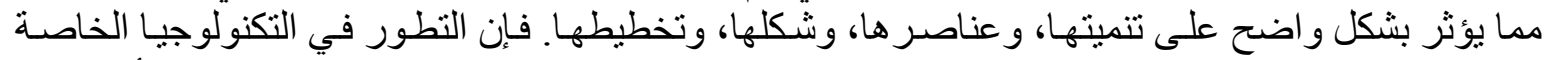

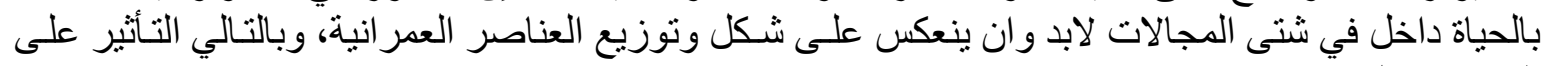
المدينة بشكل عام. دالخ في

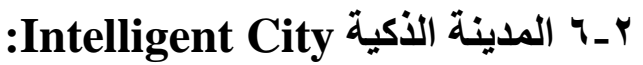

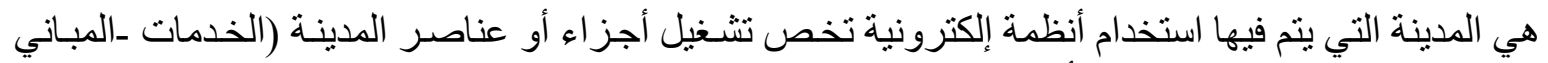

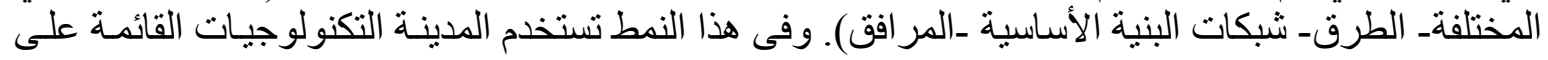

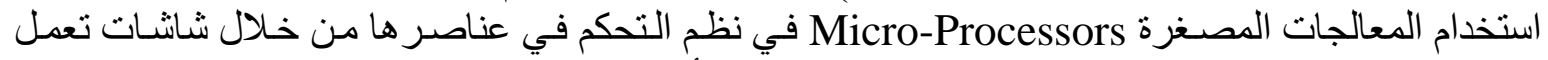

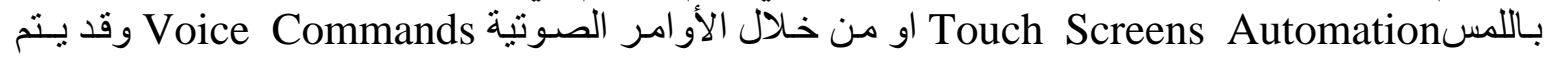
استخدام حساسات Sensors في نقاط إستر اتيجية تقوم بتغذية المنظومة بالمعلومات بشكل مستمر.

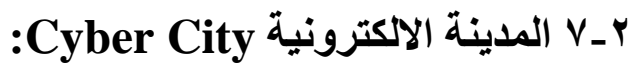

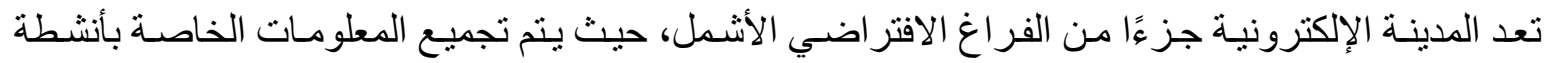

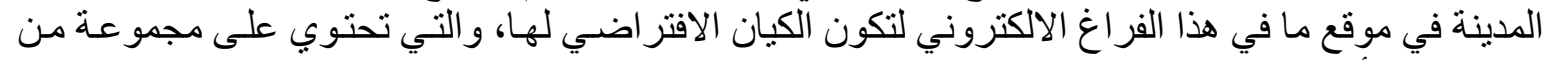

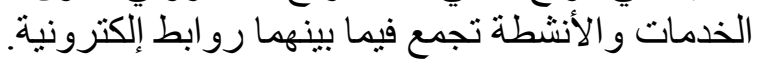

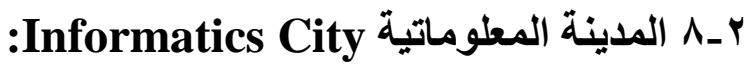

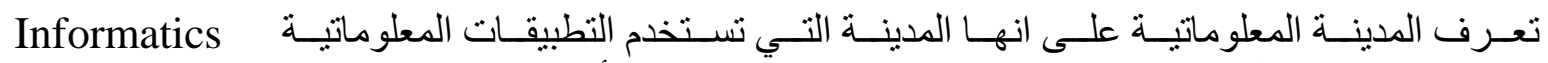
Applications

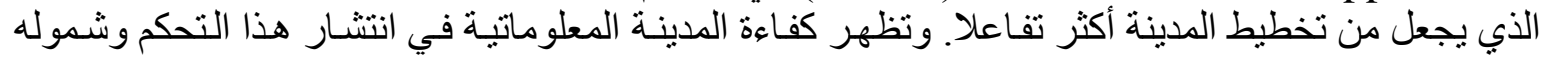

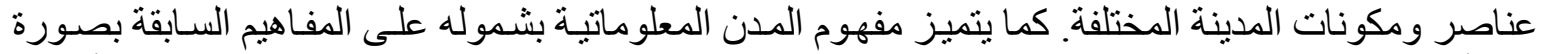

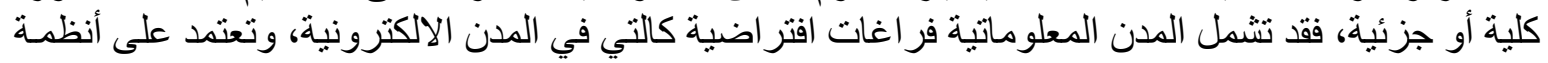
الكترونية متقدمة كالتي في المدن الذكية.

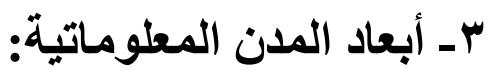

للتعرف على أطار عمل المدينة المعلوماتية بطريقة أكثر تفصيلا يمكن تقسيم در استها الي أربع أبعاد رئيسية؛: بـ إلبعد المادي للمدينة المعلوماتية:

يمثل البعد المادي للمدينة المعلوماتية في عناصر ها الوظيفية، كما يشكل تصور الفكر التخطيطي لها كالتالي:

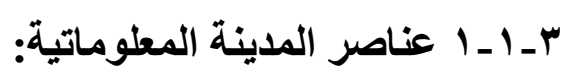

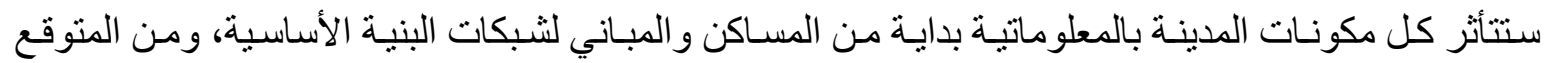

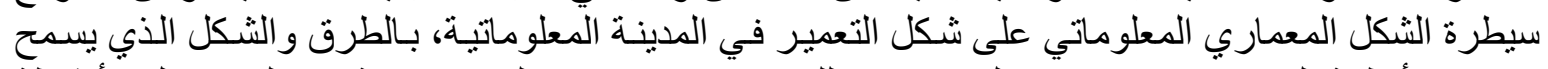

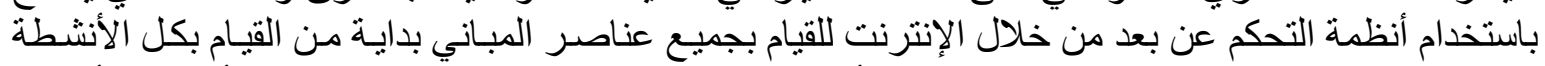

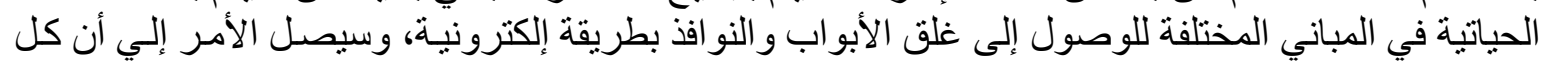

\footnotetext{
"احمد حلمي محمد، "الاعتبارات التخطيطية والتصميمية لمراكز الخدمات بالتجمعات العمرانية الجديدة في عصر المعلومات"، رسالة

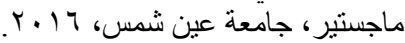
كانوبي محمد حسن - المدينة المعلوماتنية - بحث منشور في: ندوة التنمية العمر انية في المناطق الصحر اوية ومشكلات البناء بها وزارة الأشغال

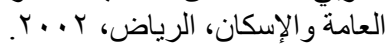


هذه الخدمات داخل المدينة ستعمل بطريقة إلكترونية بدايـة من توزيع الكهربـاء و التحكم في أنظمـة الطاقـة، للتخلص من النفايات او معالجته.

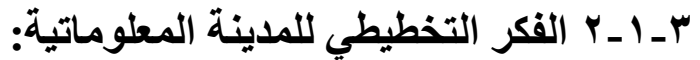

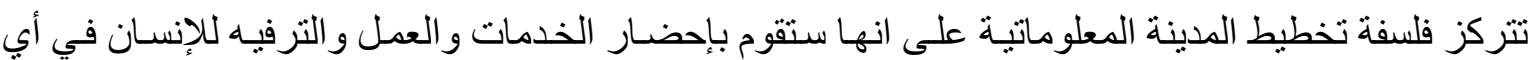

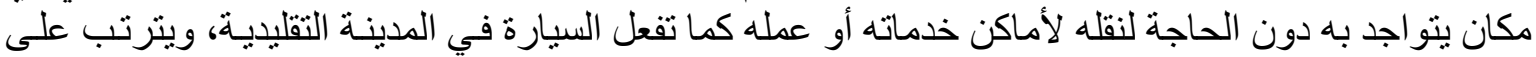
ذللك إبقاء السيار ات في ساحات الانتظار وهذا سيحل مشاكل كثيرة أخري مثل توفير زمن الرحلات التهات وازدحام الطرق وتلوث البيئة.

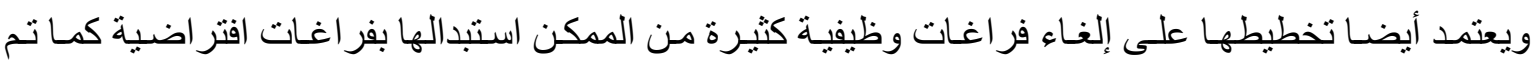

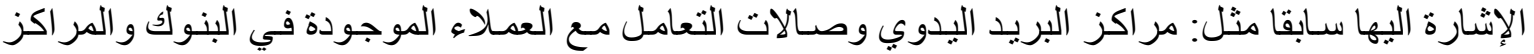

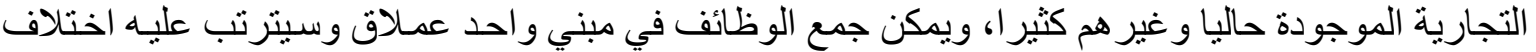

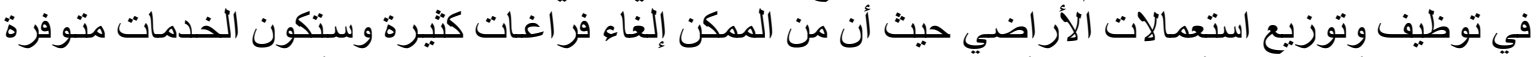

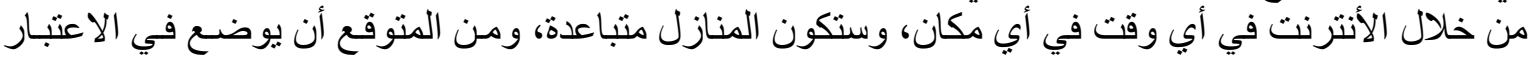

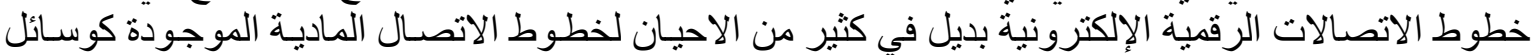
المو اصلات و الطرق و غير هما.

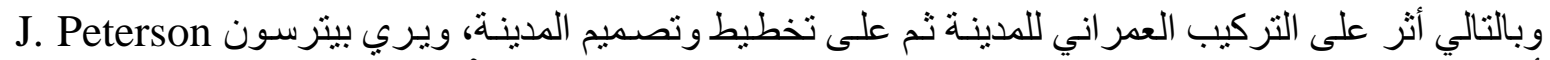

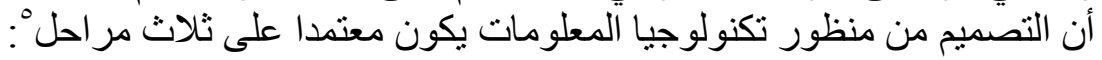

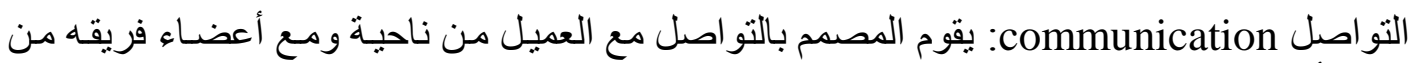
ناحية أخري ثم التو اصل مع الجهات المرتبطة بهذا التصميم.

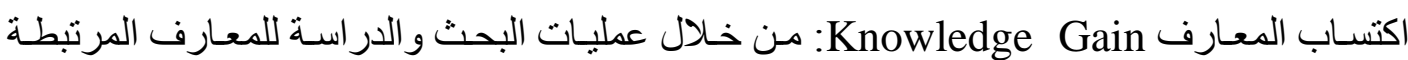

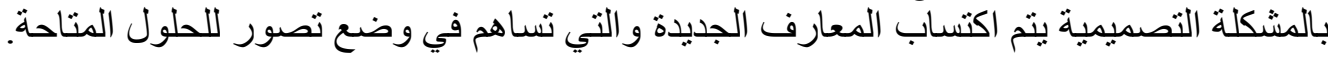

تبادل المعارف Knowledge Exchange: عن طريق الحوار يتم التو اصل بين الجهات وتبديل

و انتقال المعارف بين المصمم وفريقه التصميمي و الجهات المشاركة في العملية التصميمية.

r r ب البعد البيئي للمدينة المعلوماتية:

يمثل البعد البيئي للمدينة المعلوماتية الو عاء العمر اني الذي يحتوي على أنشطتها المختلفة، ويعد اهم عناصر

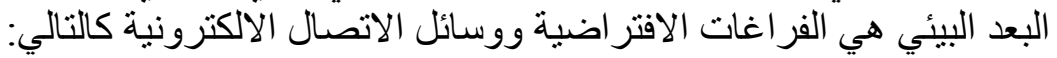

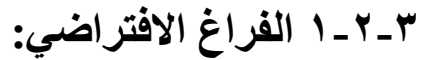

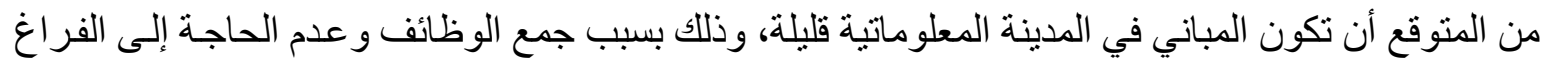

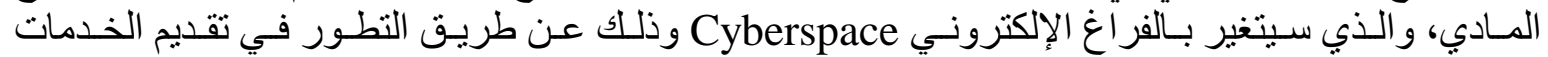

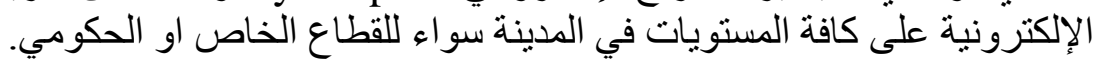

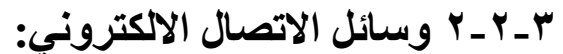

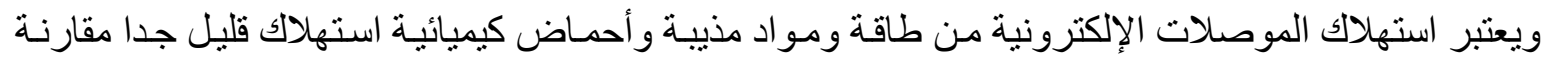

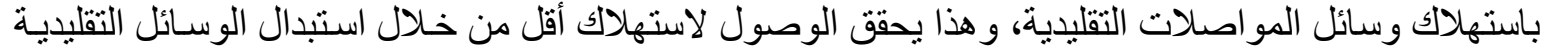

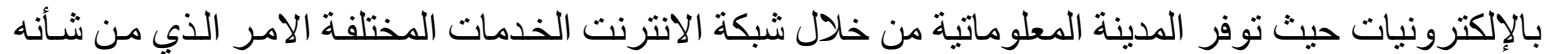

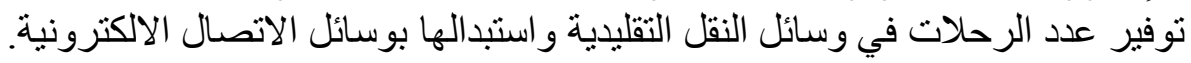

\footnotetext{
${ }^{5}$ J. Peterson, "Information Methods for Design and Construction", New York, 198•.
} 


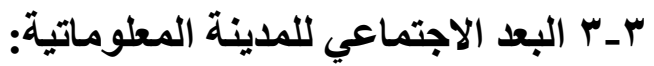

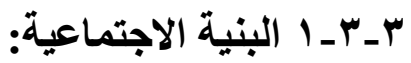

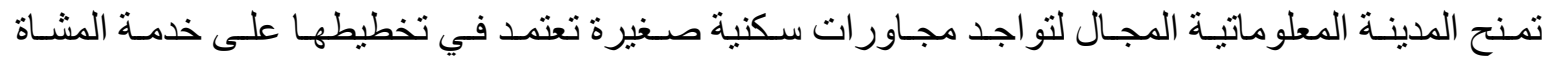

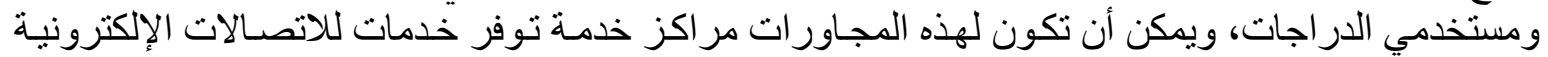

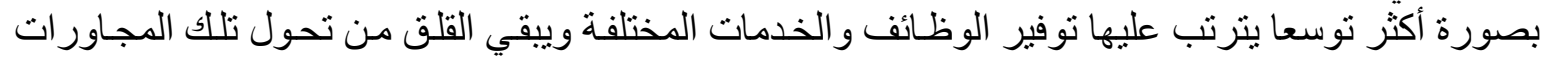

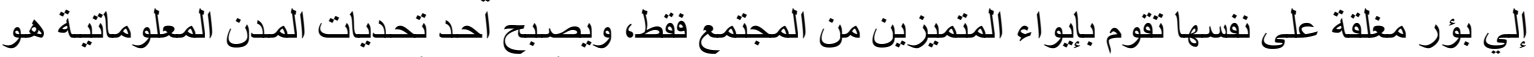

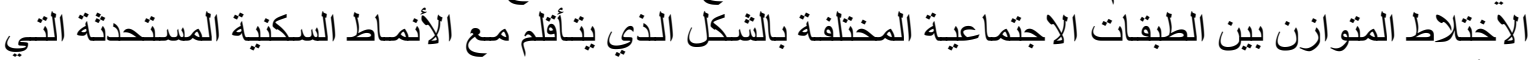
تنشأ مع الثورة المعلوماتية.

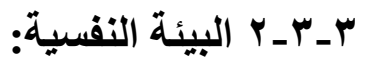

يعد احدى مسـاوئ المـدن المعلوماتيـة ان المؤشـرات تنـزر بزيـادة التفكلك الأسـري حيث إن وسـائل الاتصـال

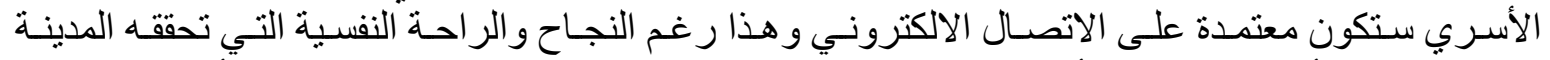

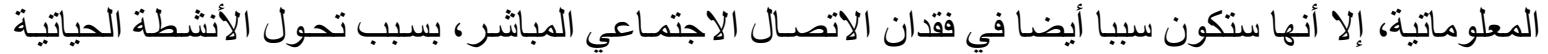

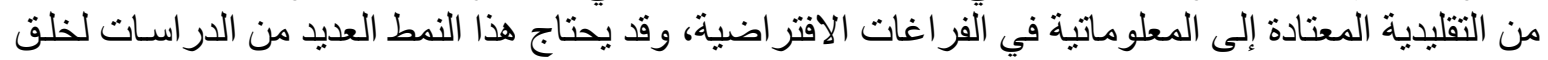
بيئة اجتماعية متزنة.

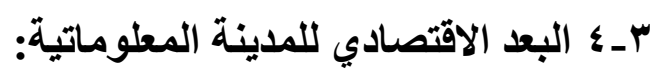

ب-4-1 القاعدة الاقتصادية:

تعتمد البنيـة الاقتصـادية للمدينـة المعلوماتيـة على نظريـة W.J.T. Mitchell وهي اقتصـاد الحضور New Economy of Presence

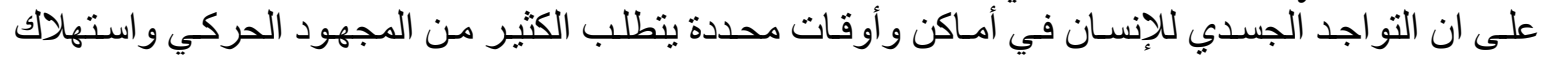

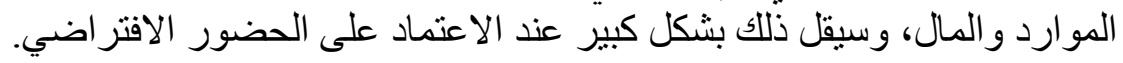

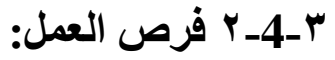

أكثر ما يؤرق الحكومات في تطبيق نموذج المدن المعلوماتية هو معدل البطالة، حيث ان الوظلائف الالكترونيـة

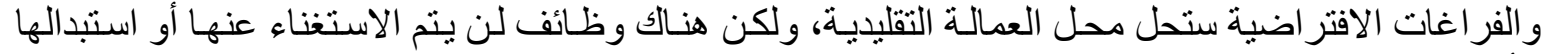

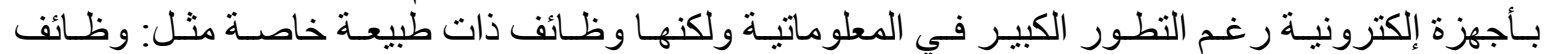

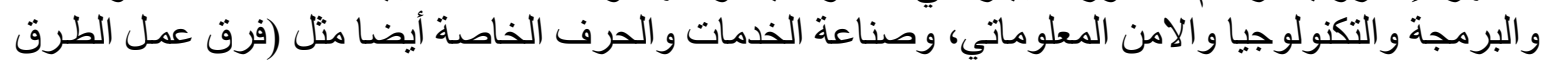

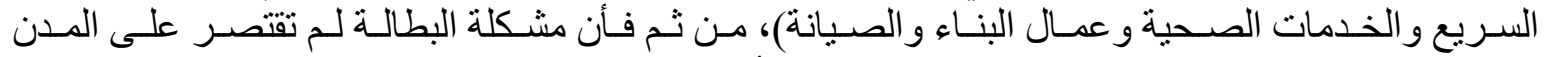
المعلوماتية فقط ولكن الامر يستدعى الدر اسة والتو عية بأهمية الوظائف المستقبلية.

\section{عـ المعلوماتية والأنثطة العمرانية:}

تظهر إمكانيات المعلوماتية وتأثير ها على المدينة عن طريق القيام ببعض الأنشطة الحياتية اليومية، حيث تقوم

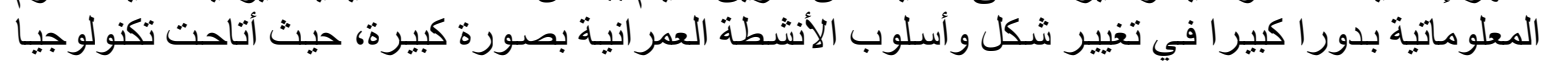

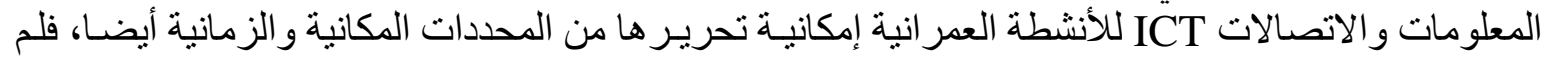

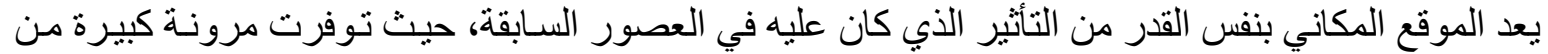

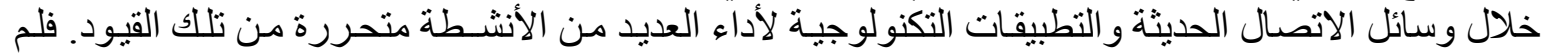

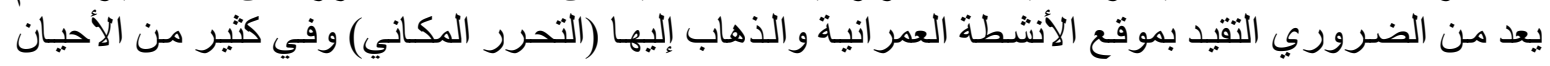


أيضـا لم يعد من الضـروري وجود طرفي الخدمـة ـ مقدم الخدمـة ومستقبل الخدمـة ـ في نفس الوقت لإتمـام

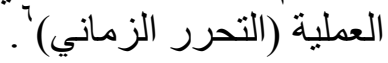

ولقد تم وصف هذا التنسيق بـ Hyper Coordination ونتج عن هذه التغيير ات العديد من التأثنير ات على التى التي

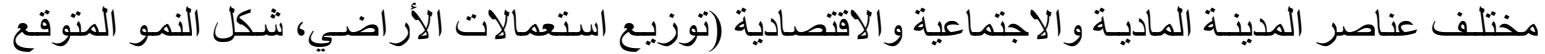

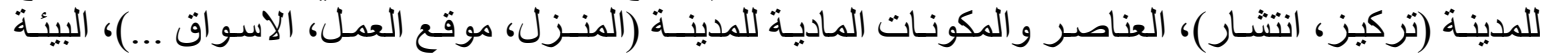

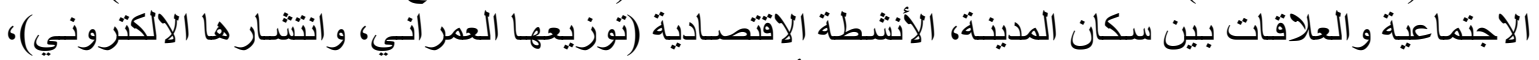

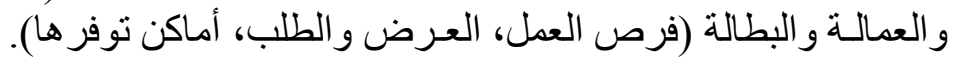

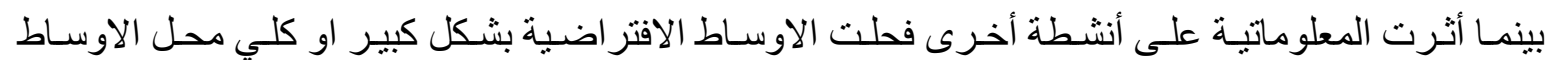

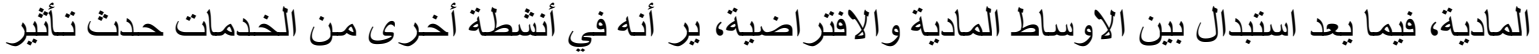

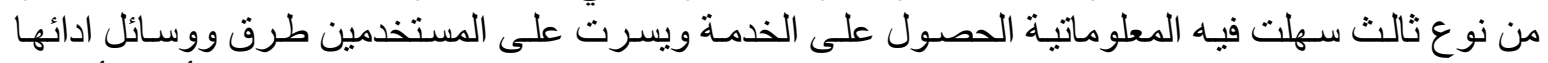

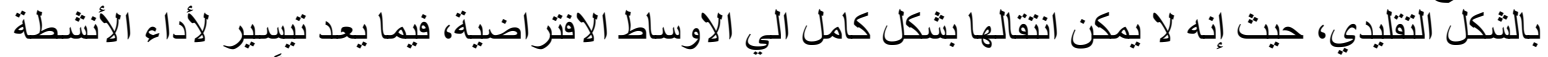

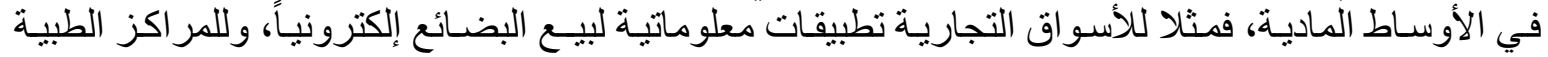

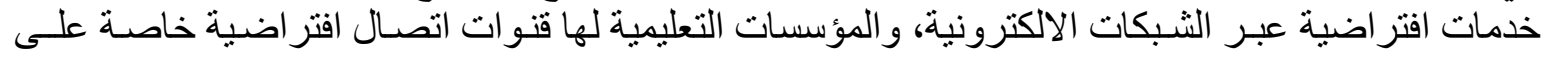

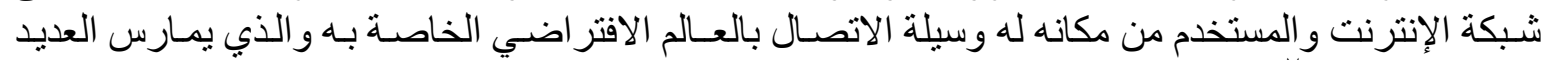

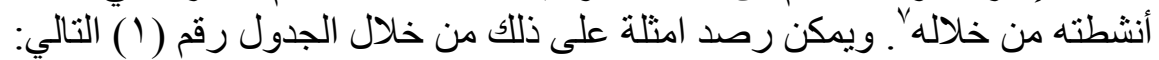

\begin{tabular}{|c|c|c|}
\hline التحولات المتوقعة في العمران & تأثير المعلوماتية & النشاط \\
\hline 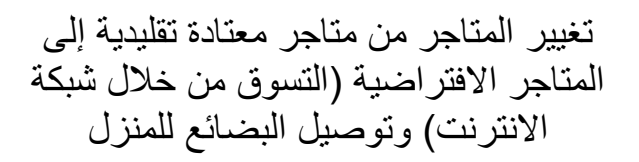 & 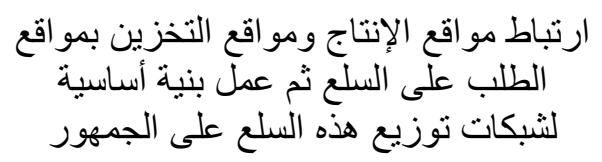 & التسوق \\
\hline وانقسام العملية التعليمية بين الفصول الافتراضية التقية & \multirow{2}{*}{ 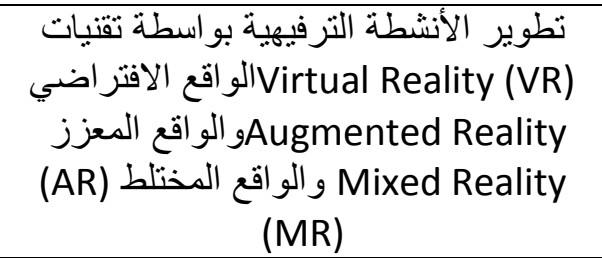 } & 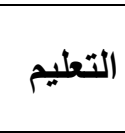 \\
\hline تحول بعض الأنشطة الترفيهية الي الفر اغات & & الترفيه \\
\hline و الزمران)، ظهُة العمل من قيودها التقليدية (المكان & 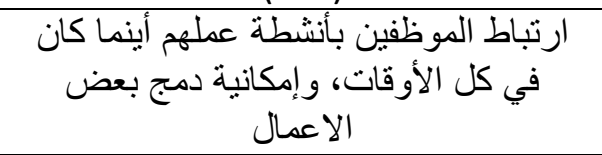 & العمل \\
\hline 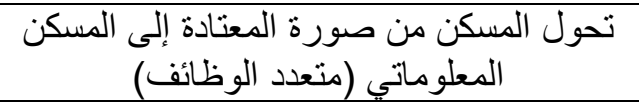 & القيام بالأنشطة اليومية من المسكن & السكن \\
\hline
\end{tabular}

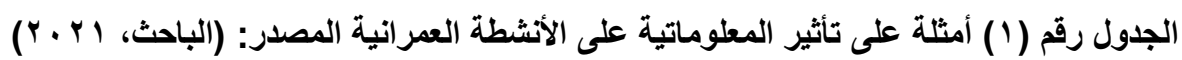

ــ ا التغيير في خصائص الأنشطة:

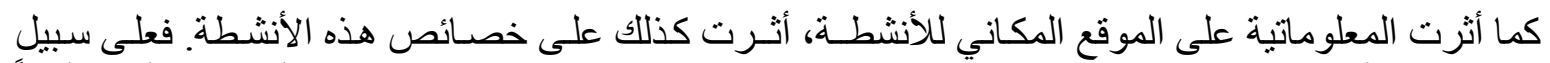

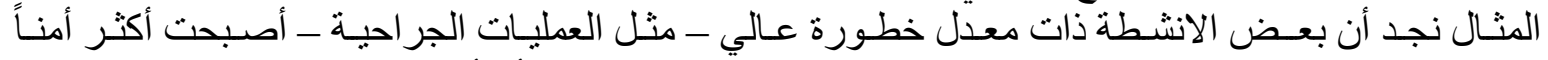

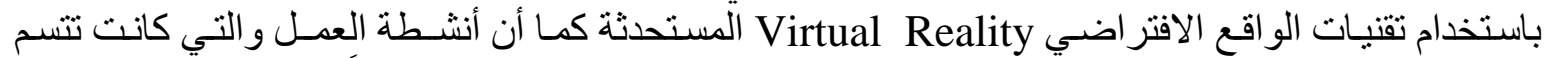

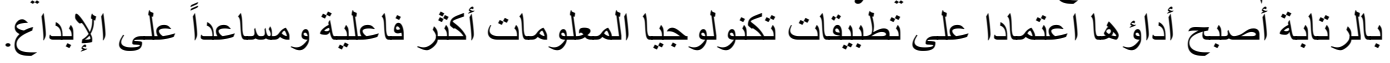

"عمر محمد الحسيني، "تأثثير عصر المعلومات على الفراغات العمر انية للمر اكز الخدمية"، ورقة بحثية مجلة كلية الهندسة جامعة حلوان، 
ويمكن اعتبار ان هناك عالم مواز نعيش فيه، وهو عالم افتر اضي Virtual World غير و اقعي و الذي يعرف الإف

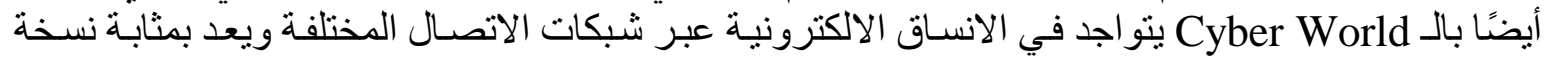

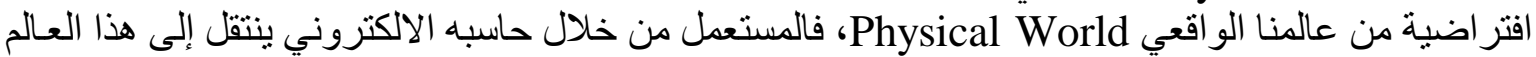

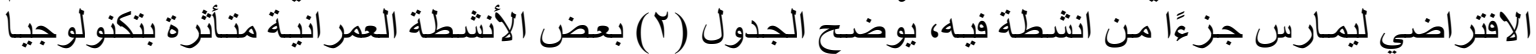
المعلومات و الاتصالات ICT بصور الإنسات مختلفة.

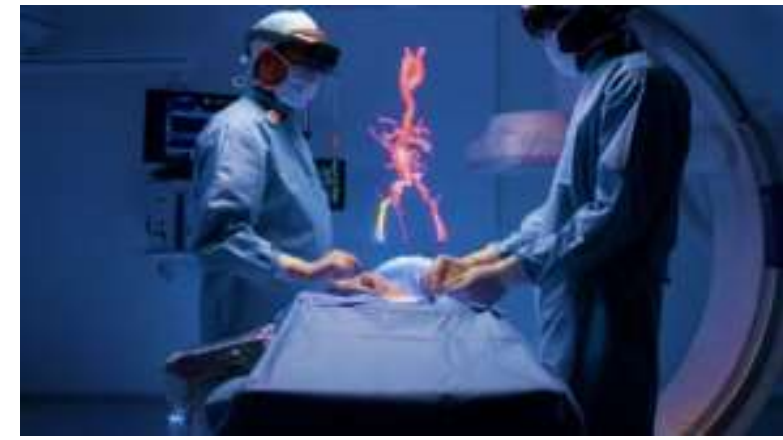

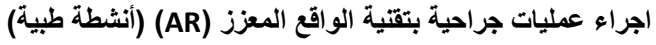

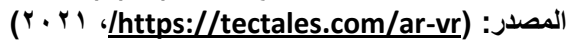

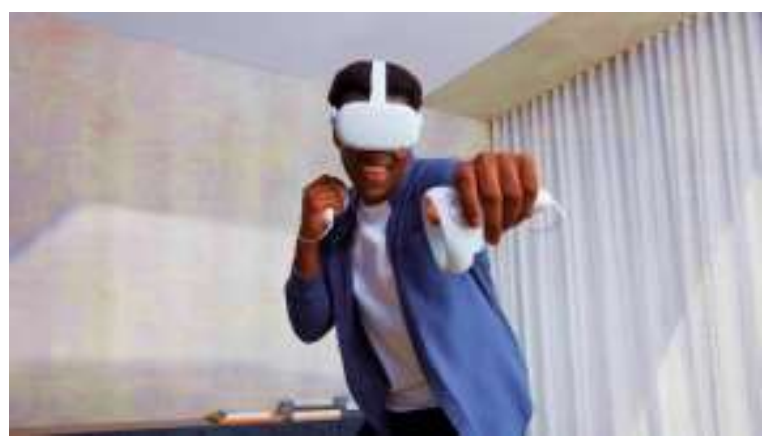

العاب ترفيهية بتقتيات الواقع الافتراضي (VR) (أنثطة ترفيهية)

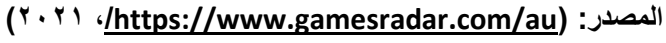

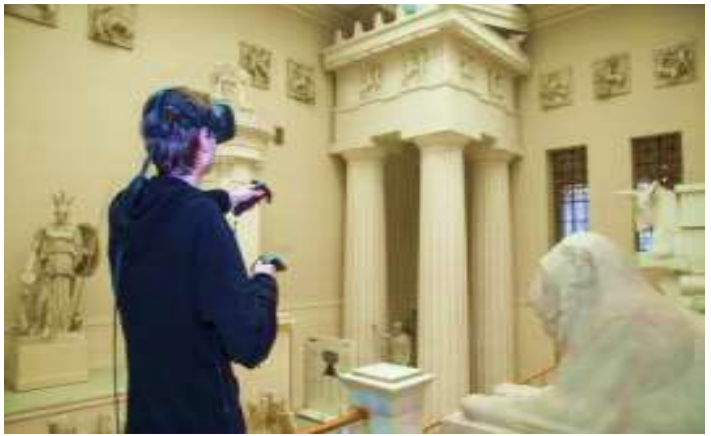

متحف افتراضي (الانشطة الثقافية)

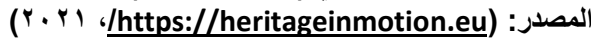

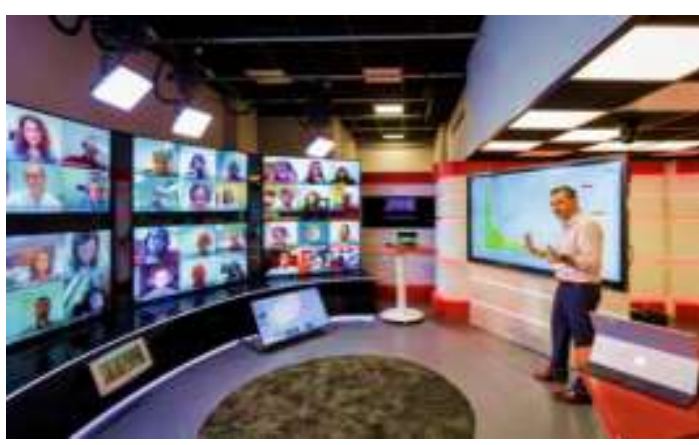

فصل افتراضي (أنشطة تعليمية)

المصدر: (r.r)، (rhttps://av-news.co.za)

جدول رقم (Y) بعض الأنثطة العمر انية متأثرة بتكنولوجيا المعلومات والاتصالات

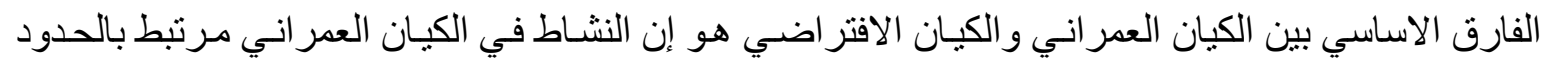

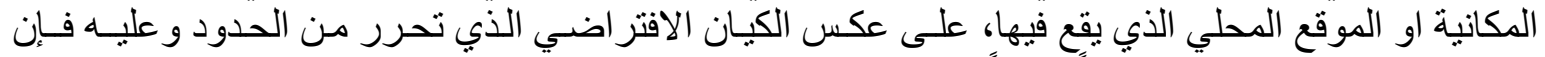

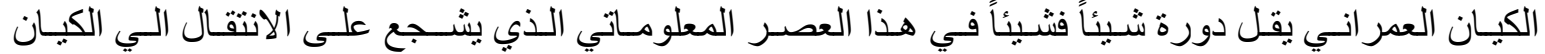

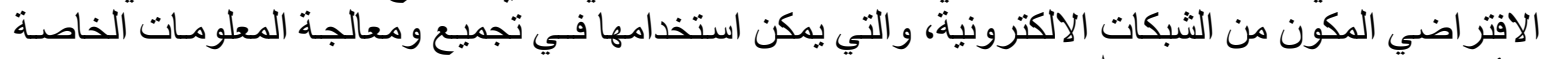

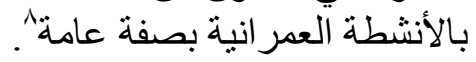

ولكن ماز الت العلاقة بين الكيان الافتر اضي وبين الكيان العمر اني علاقة تكاملية وذلك على النحو التالي:

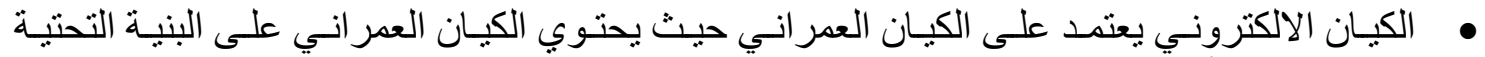

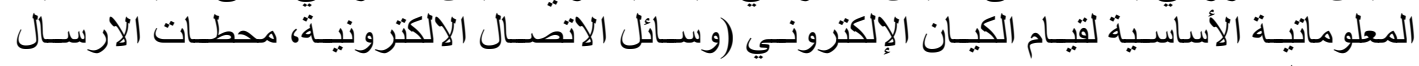
و الاستقبال).

^حمد أنور عبد الله، "تخطيط المدن في حقبة تكنولوجيا المعلومات"، رسالة دكتور اة غير منشورة، جامعة القاهرة، r . . r. 
الإنسـان كائن مـادي و لا يستطيع العيش في الأوسـاط الافتر اضية فقط حيث يحتـاج الكيان العمر اني التقليدي.

أصبح الكيان العمر اني يعتمد بشكل اساسي على وجود نظيره الافتر اضي في أداء وظائفه، حيث تتيح

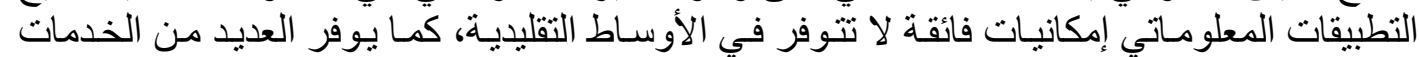

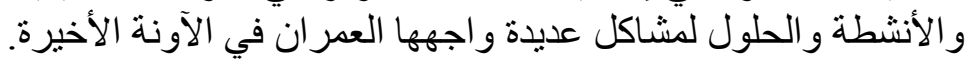

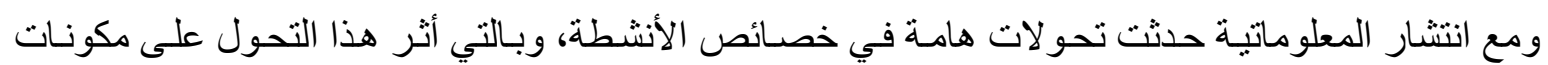

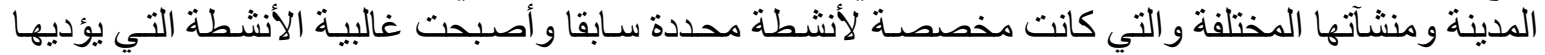

الإنسان داخل المدينة تتفق في سمات متعددة وتو اجه تحديات خاصة.

\section{ع-r سمات الأنشطة المعلوماتية:}

التحـرر مـن القيـود الزمانيـة و المكانيـة للأنثــة اعتمـادا على الاتصــال الإلكترونـي بـين هذه مقدم

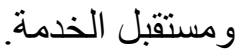

إمكانية تعدد وظائف المكان الواحد واستيعابه لأنشطة مختلفة الأمر الذي من شـأنه اختلاف ورؤيـة

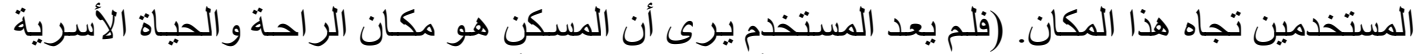

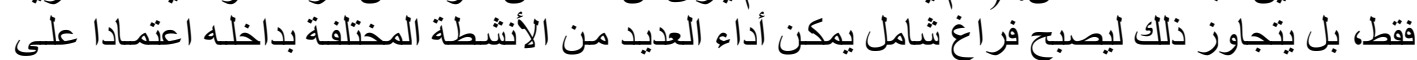
تكنولوجيا المعلومات و الاتصالات).

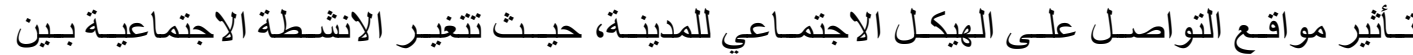
المستخدمين كما تأثر التكوين الاجتماعي لهم.

لم تعد الانشطة على علاقة بمحيطها العمر اني فحسب، بل أصبـح هناك الاتهـام بـالغ بعلاقتها بـالمحيط الإلكتروني وشبكات الاتصال وكيفية تفاعلهما معًا.

انعكاس سهولة تداول المعلومات ومعالجتها كما وكيفًا على فاعلية أداء الأنشطة الحياتية المختلة. أصبحت تتيح الأوسـاط الافتر اضية للأنشـة عدد لانهائي مـن الحلول يتم توظيفها وفقًا للظروف

\section{ع-ب تحديات الأنشطة المعلوماتية:}

تو اجه الأنشطة المعلوماتية باعتبار ها أنشطة حديثة نسبيا الكثير من التحديات، تتمثل تلك التحديات التحة في قصور

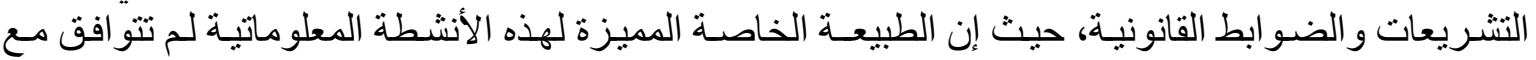

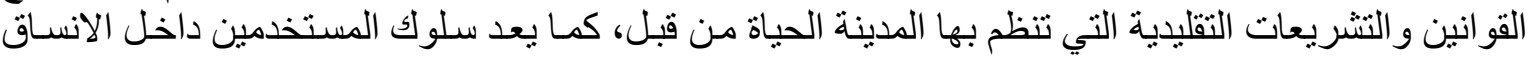

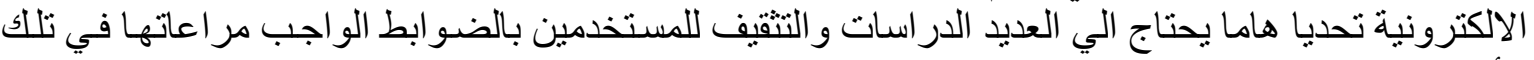
الأوساط الافتر اضية.

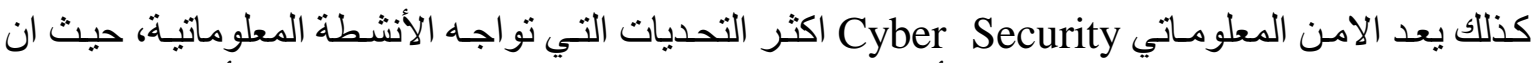

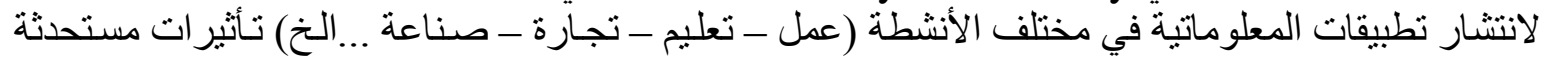

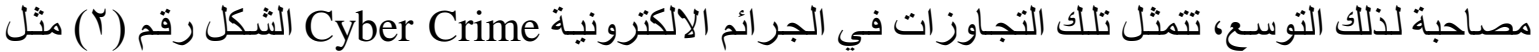

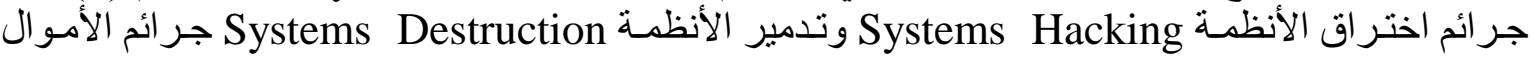

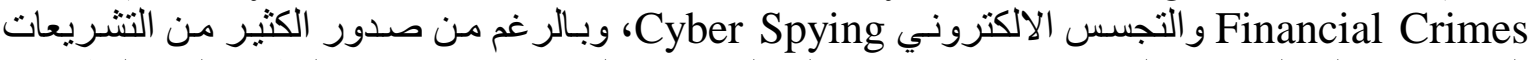

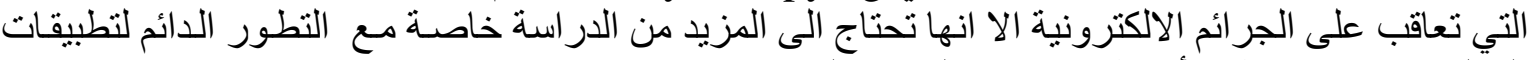
المعلوماتية سوف تظهر أنماط جديدة من الجر ائم الواجب الجب مكافحتها. 


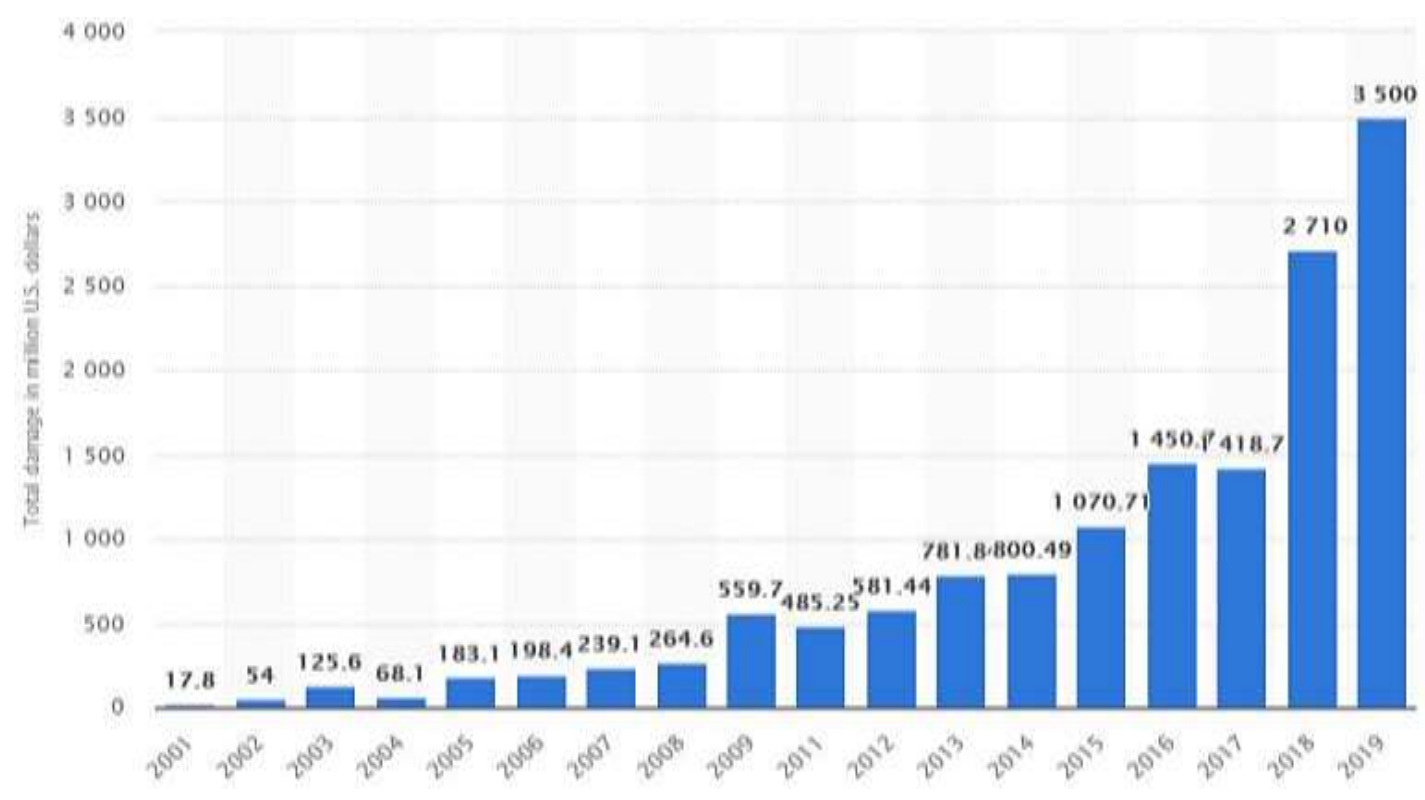

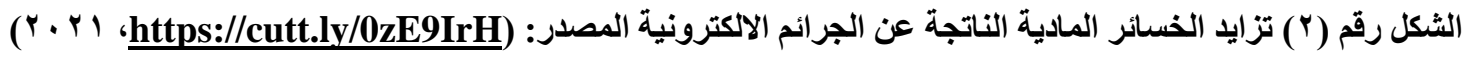

جدير بالذكر أن هذه الأوساط الافتر اضية لا تز ال في بعض الأحيان تعتمـد على بعض من مكونـات الاوسـاط

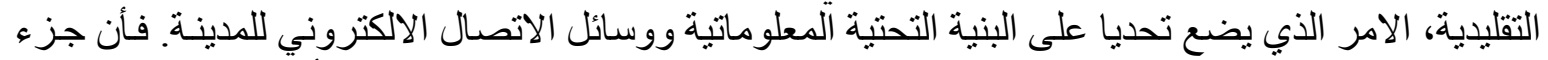

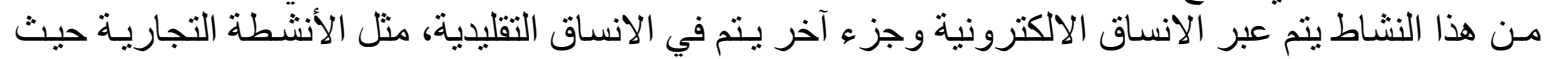

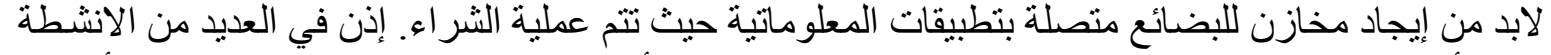

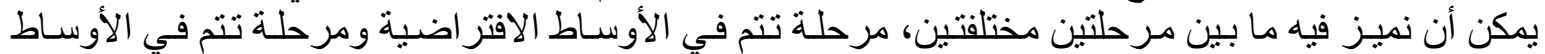
التقليدية.

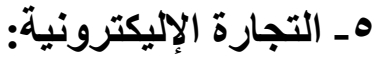

تعد التجارة الاليكترونية واحده من اهم التطبيقات لتكنولوجيا المعلومات والاتصالات وتشهـ التجارة

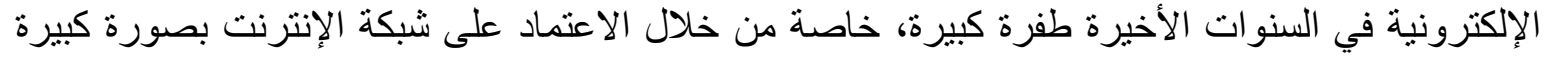

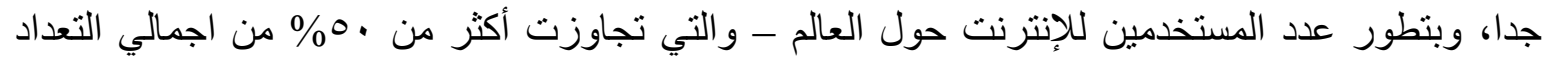

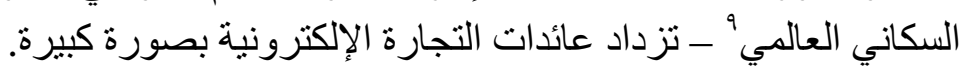

كذلك فإن الإحصاءات تؤكد على أن حجم التجارة الإلكترونية ينمو بشكل متسارع عالميا حتى بلغ ما يقارب

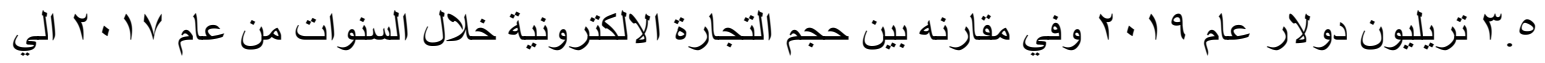

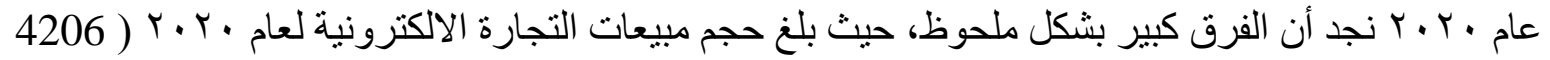

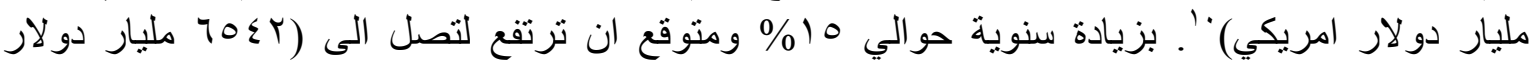

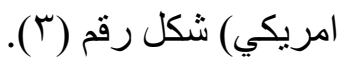

\footnotetext{
${ }^{9}$ Organizational Website - World Bank - https://data.worldbank.org/indicator/it.net.user.zs - Individuals using the Internet (\% of population) - 2021.

${ }^{10}$ Commercial Website - Oberlo - https://www.oberlo.com/statistics/global-ecommerce-sales, 2021.
} 


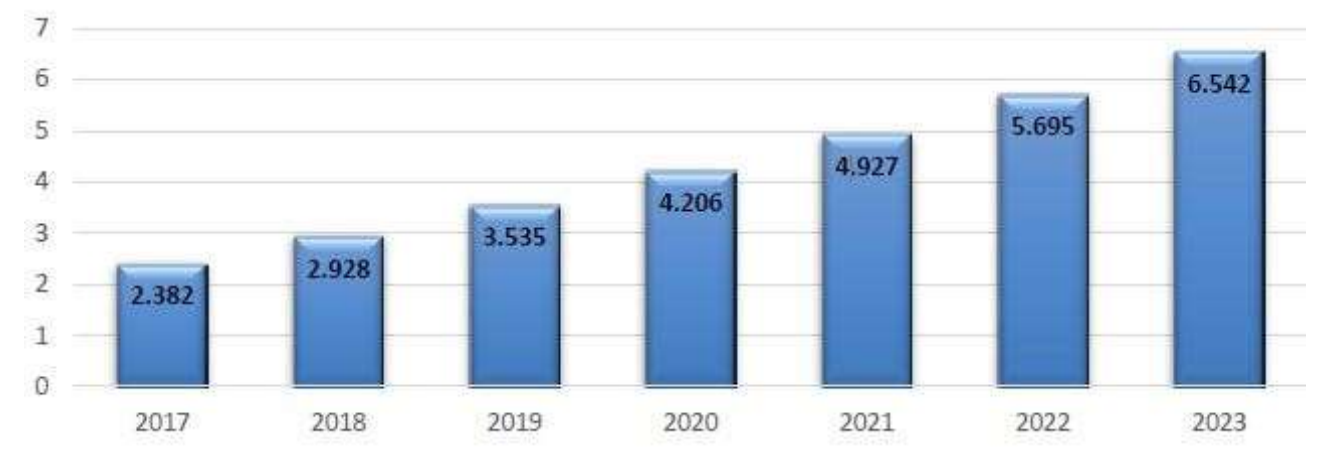

\section{الثكل رقم (ץ) يوضح تزايد مبيعات التجارة الاكترونية سنويا المصدر: \\ ( $r \cdot Y$, ،/https://www.oberlo.com/statistics/global-ecommerce-sales)}

\section{1-1 التجارة الاكترونية في ظل جائحة كورونا (كوفيد-9 1):}

أثرت جائحة فيروس كورونا المستجد COVID-19 منذ ظهور ها في نهاية عام 9 أ. 19 على القرارات

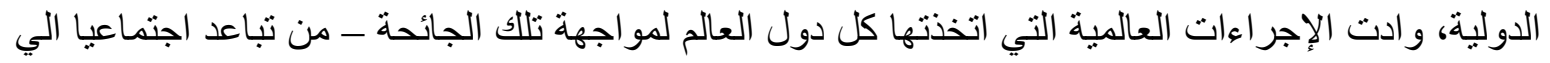

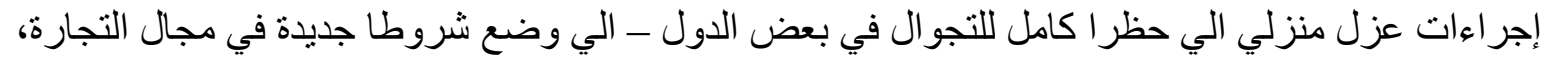

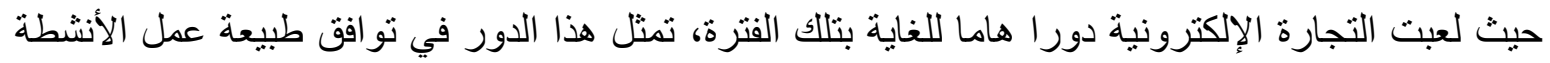

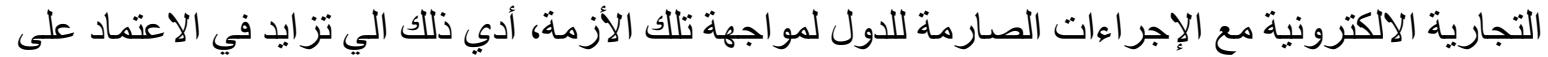

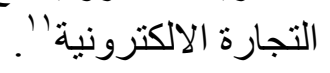

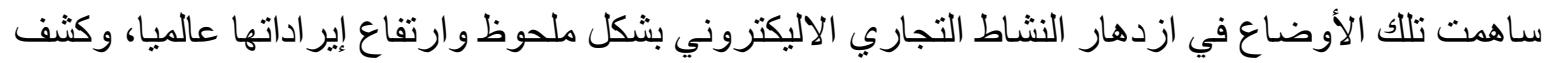

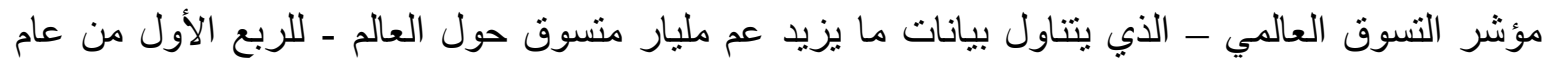

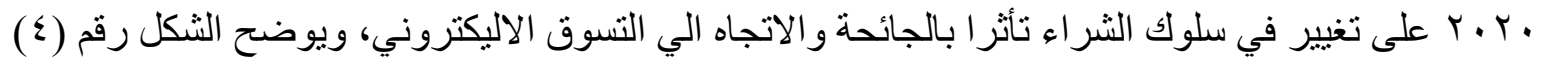

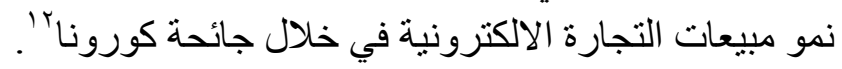

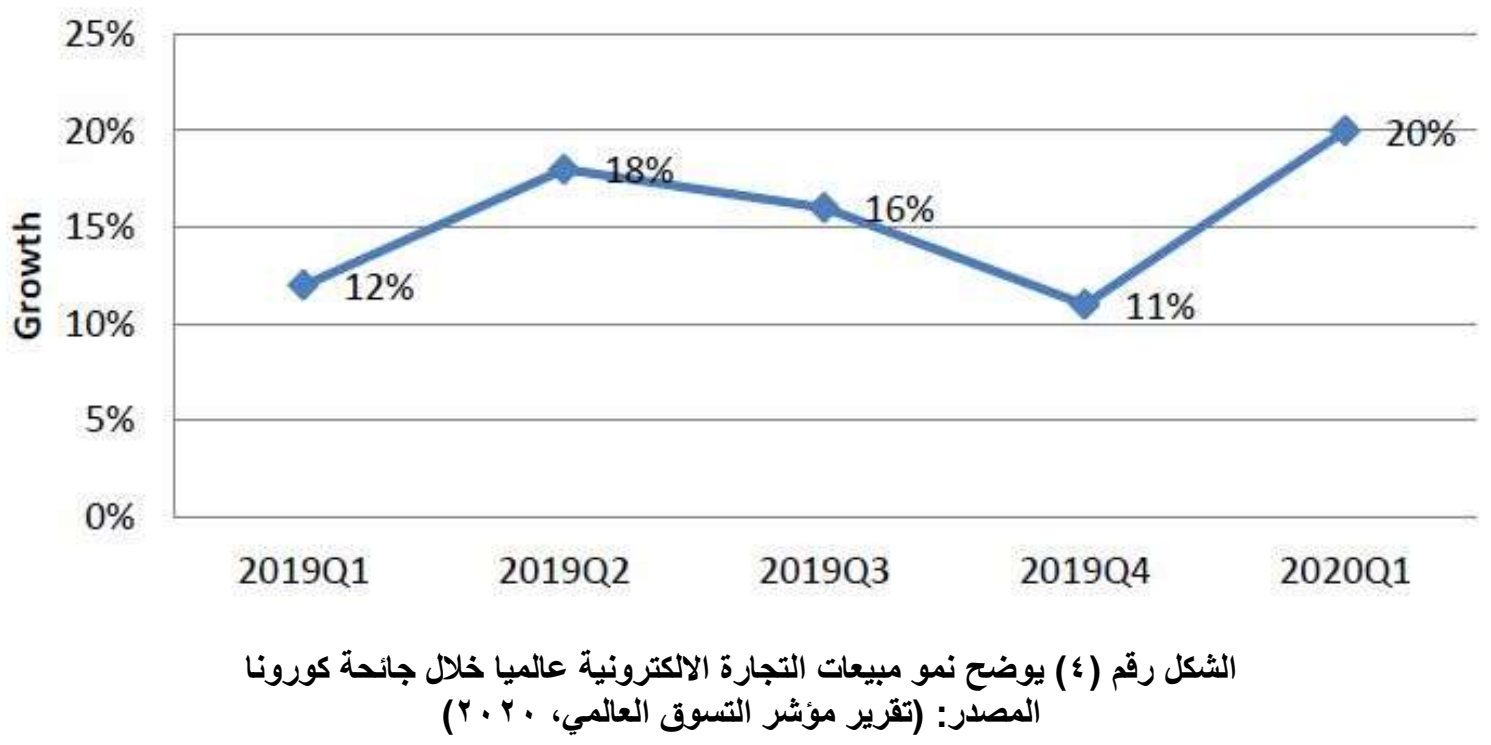

11 - United Nations conference on trade and development, "COID-19 and E-Commerce impact on businesses and policy responses",2020.

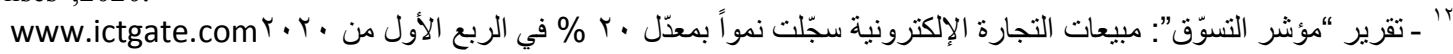




\section{ب_ • تأثير التجارة الاليكترونية على الأنشطة التجارية ـ دراسة حالة (الولايات المتحدة الامريكية):}

تعد الو لايات المتحدة الامريكية أكثر الدول تطورا في تكنولوجيا المعلومات والاتصالات والبنية التحتية

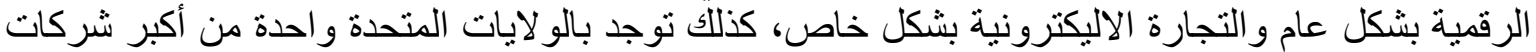

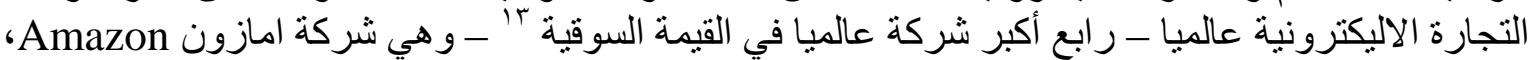

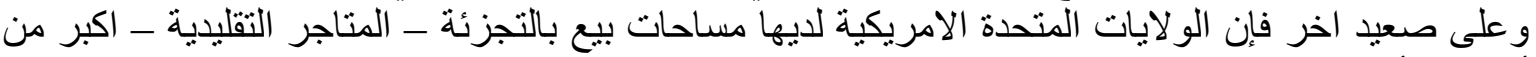

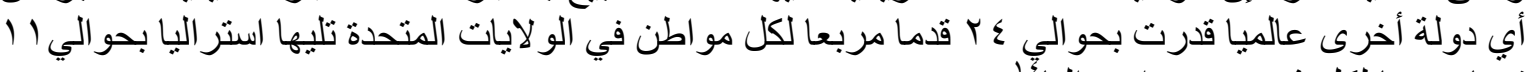
قدما مربعا لكل شخص في استر الياءً.

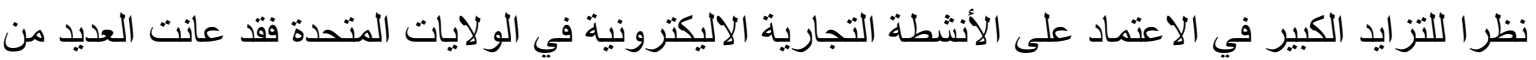

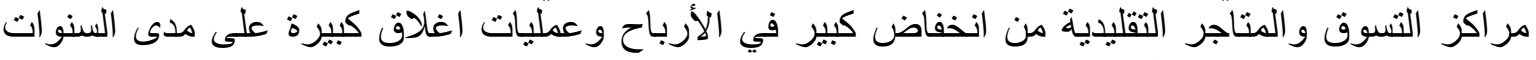

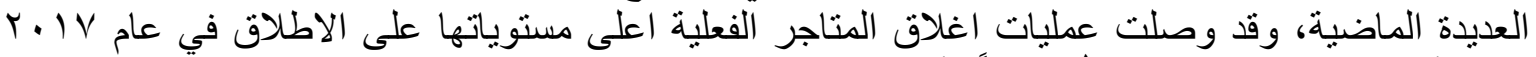

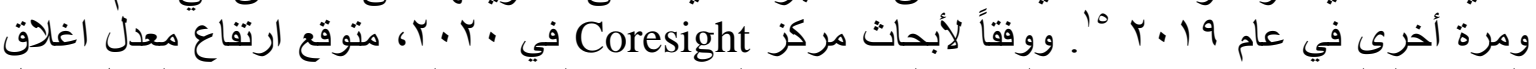

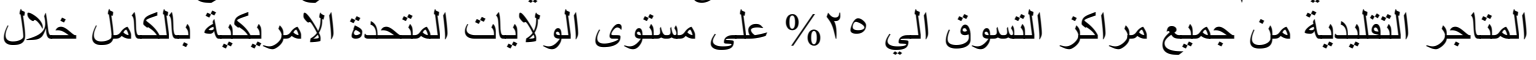
الخمس سنو ات القادمة.

على الرغم من كل هذا التر اجع والانخفاض في حجم النشاط التجاري التقليدي الا أنه حجم المبيعات التجارية

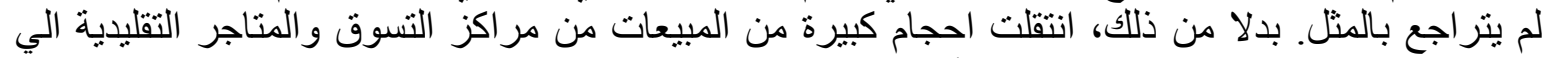

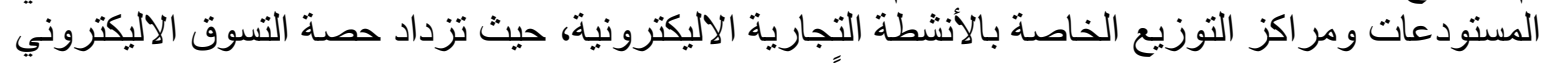

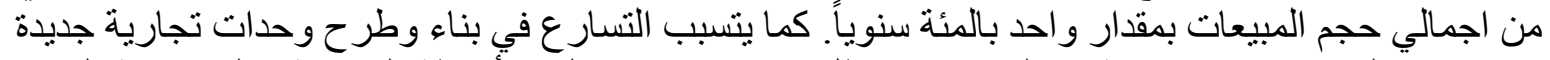

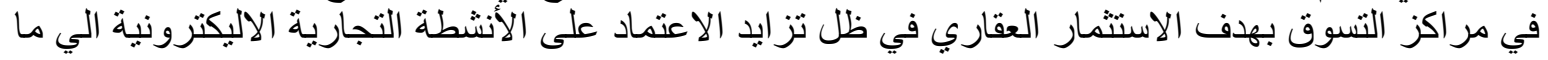

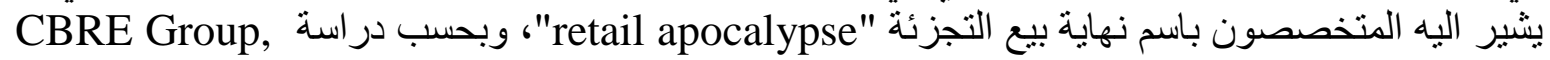

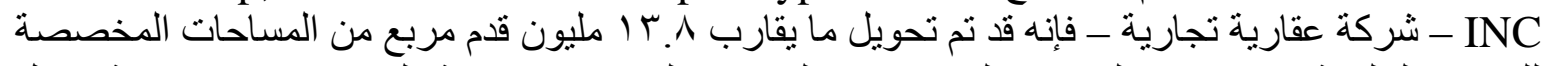

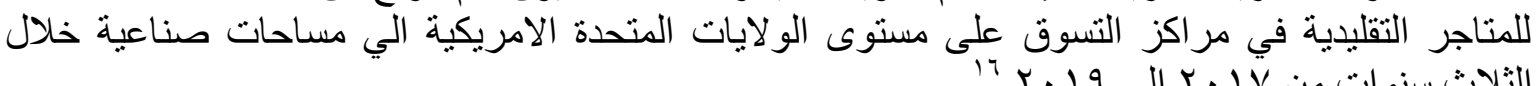

اعتمادا على أماكن تركيز البيع من خلال المنصات الاليكترونية وأماكن اغلاق المتاجر التقليدية فإنه قد يحدث التهاث

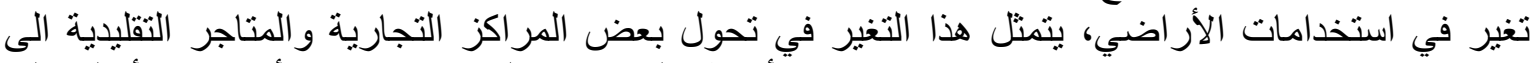

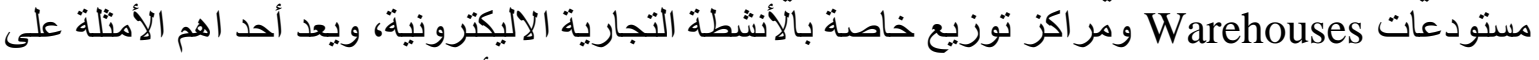

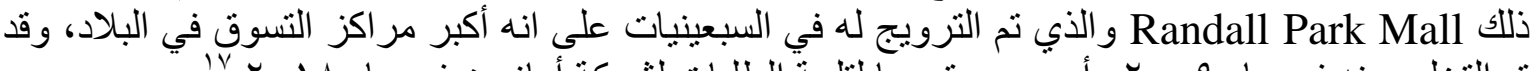

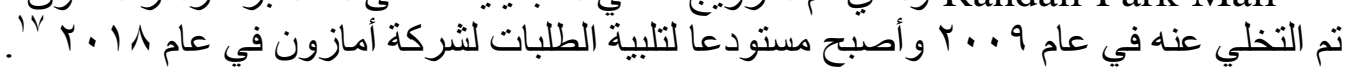

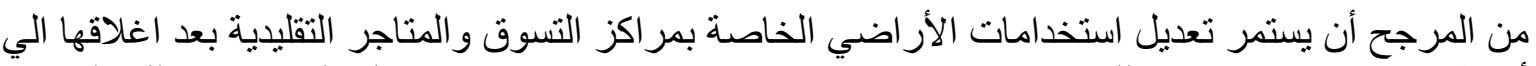

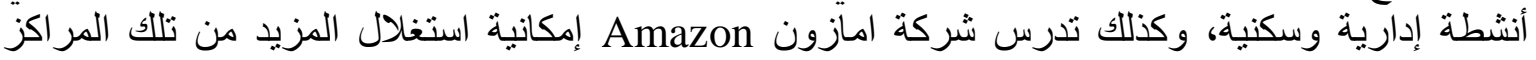

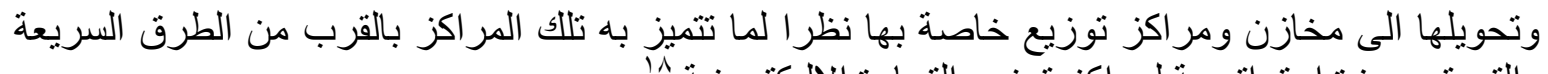

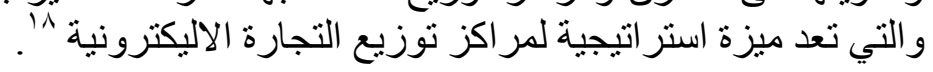

\footnotetext{
${ }^{13}$ Commercial Website - Forbes - https://www.forbes.com/the-worlds-most-valuablebrands/\#538e5012119c - 2021.

${ }^{14}$ Robin Wigglesworth, "Will the Death of U.S. Retail be the Next Big Short?," Financial Times, July 16, 2017.

${ }^{15}$ Laura Kusisto, “Amazon and Big Apartment Landlords Strike Deals on Package Delivery," Wall Street Journal, October 17, 2017.

${ }^{16}$ Cailin Crowe, "Miami Pilots E-cargo Bikes to Reduce Congestion, Pollution," Smart Cities Dive, May 18, 2020

17 “Mayor de Blasio Announces Commercial Cargo Bike Program to Reduce Delivery Congestion," New York City Department of Transportation, December 4, 2019.

${ }^{18}$ City of Boston, "City releases RFI for electric cargo bikes as a delivery solution," July 20, 2020.
} 


\section{7ـ ت تأثيرات المعلوماتية على المراكز التجارية:}

لقد ترتب على استخدام المعلوماتية وتكنولوجيا المعلومـات ووسـائط المعلومـات في مجال الأنشطة و الخدمات

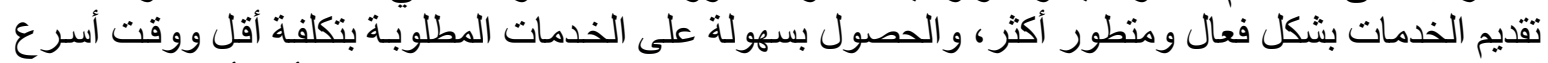

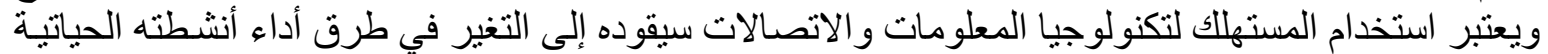

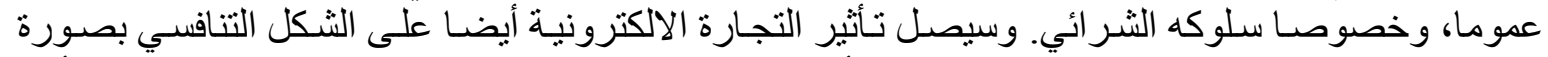

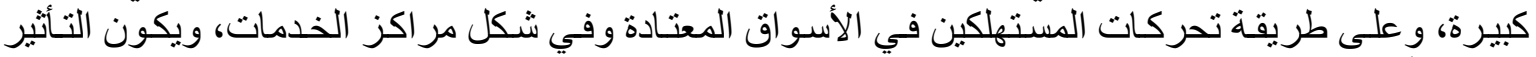

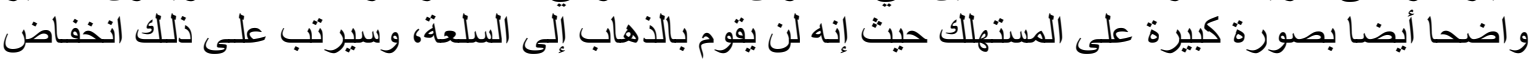

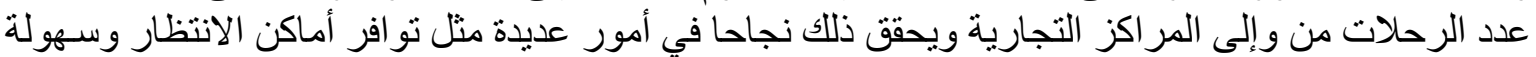

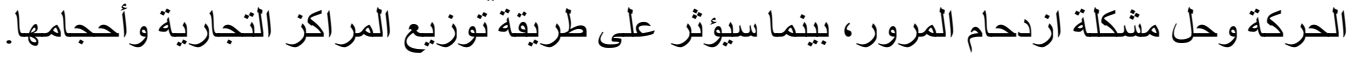

\section{צ-1 التغيير في المكونات الأساسية لغناصر المراكز التجارية:}

بينما الاعتماد الكبير على الإلكترونيات في القيام بالأنشطة الحياتية سيغير عناصر ومحتويـات المباني الخدميـة

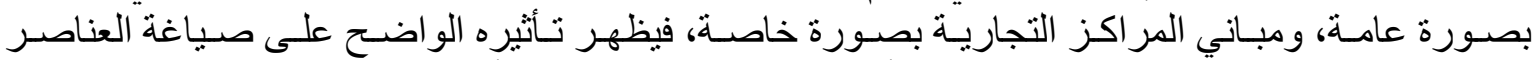

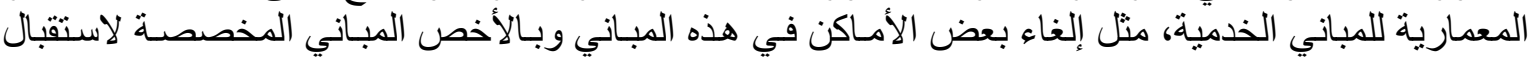

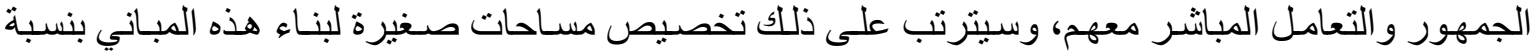
كبيرة، وخفض تكلفة بناء هذه المباني.

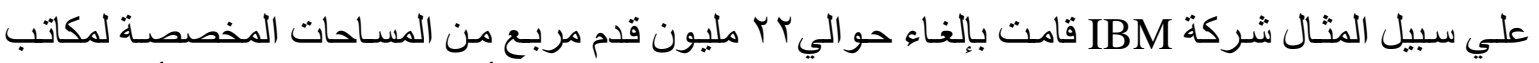

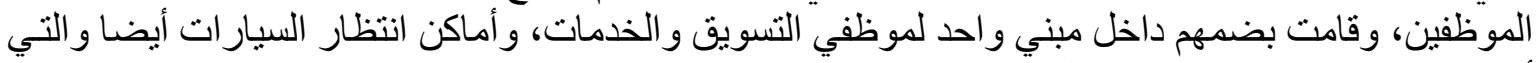

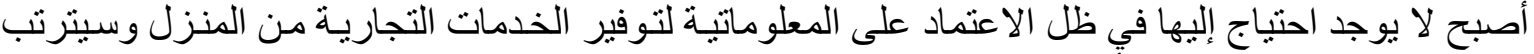
عليه تقليص مساحة المتجر و أَّاكن السيار ات الات.

\section{؟_r التغيير في المكونات التثكيلية للمر اكز التجارية:}

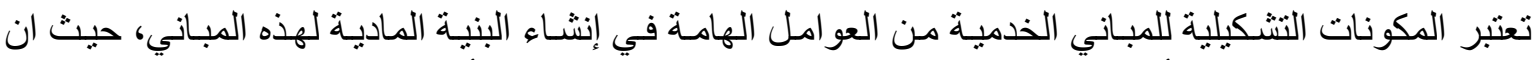

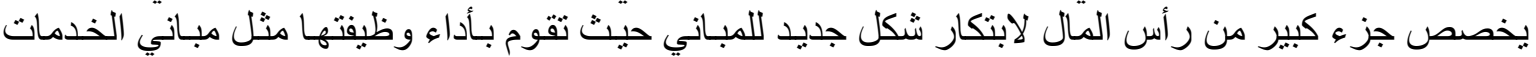

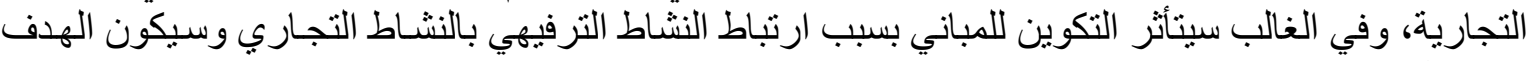
الوصول إلى طرق جذب المستهلك للمر اكز وهذا سيحتاج إلى تشكيلات معمارية حديثة و غير تقليدية.

\section{ج_r التغيير في نمط تخطيطوتوزيع المراكز التجارية:}

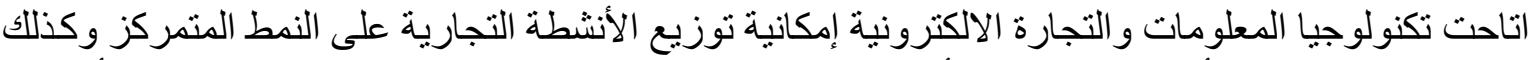

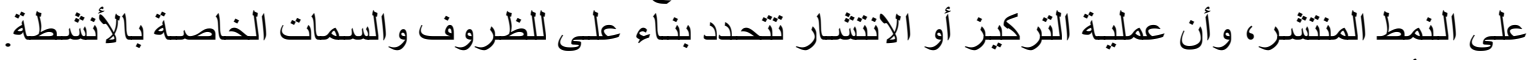

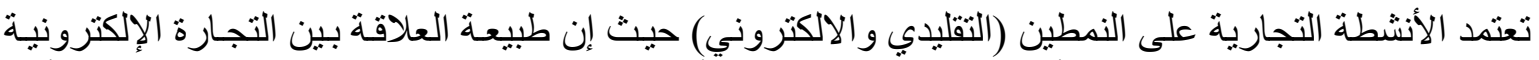

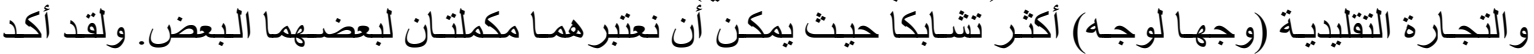
البعض هذه الفرضية على النحو التالي: (النئ

i. "The rise of electronic communications networks may well - have produced more, not less socialization, much of it face to face, ${ }^{\text {,i9 }}$.

ii. "It is also possible that telecommunications are not a substitute for face-toface interactions, but in fact these two forms of information transmission are

\footnotetext{
19 -Nigel Thrift, "New Urban Eras and Old Technological Fears: Reconfiguring the Goodwill of Electronic Things" Urban Studies, Vol. 33, No. 8, 1996.
} 
complements. If they are complements, then we should expect cities and space to get more important as information technology improves " 20.

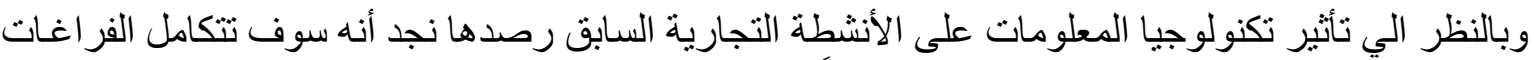

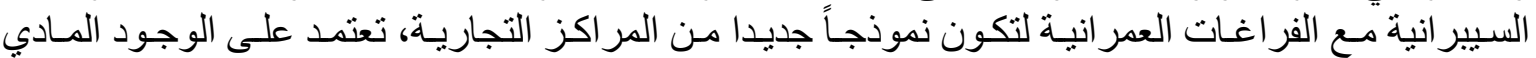

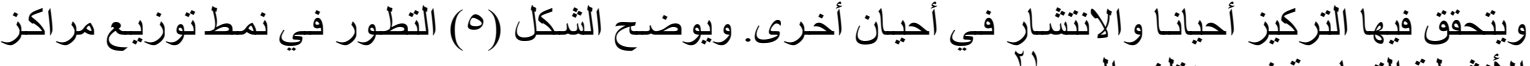

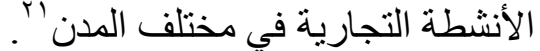

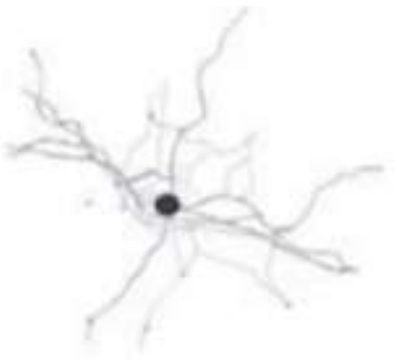

Walking City

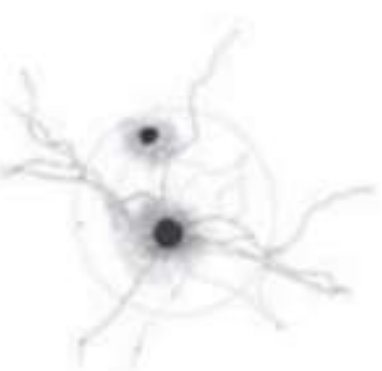

Agricultural City

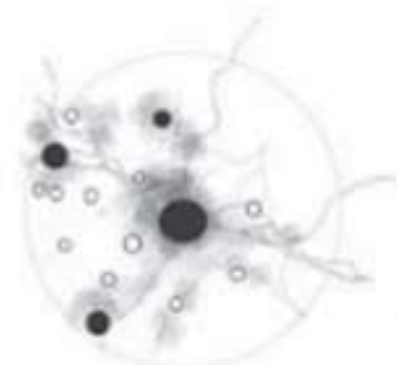

(Growth of Telecommunication Centres)
(City with Transportation)

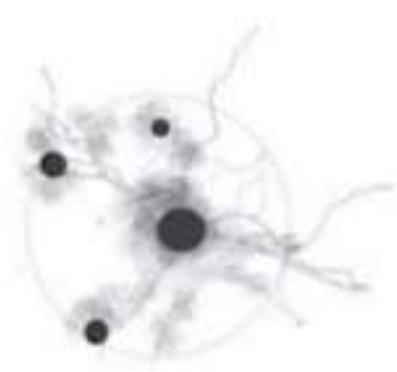

Industrial City

(Growth of Manufacturing Centres)

Telecommunication City

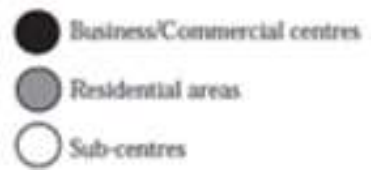

شكل رقم (•) شكل توزيع الأنشطة التجارية في المدن المعلوماتية المصدر: (Merlyna Lim, 2002)

\footnotetext{
20 - Jess Gaspar and Edward L. Glaeser, Information Technology and the Future of Cities, Harvard Institute of Economic Research, Harvard University, April, 1996.

21 - Merlyna Lim, "From Walking City to Telematic Metropolis: Changing Urban Form in Bandung, Indonesia". Critical Reflections on Cities in Southeast Asia. Brill Publisher and Times Academic Press, 2002.
} 


\section{צـ ـ تأثير التجارة الاكترونية على تكوين المدينة:}

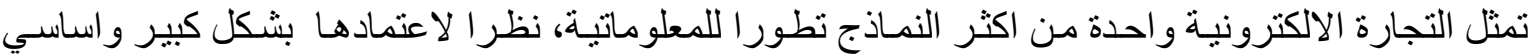

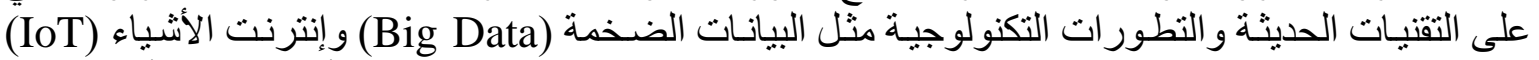

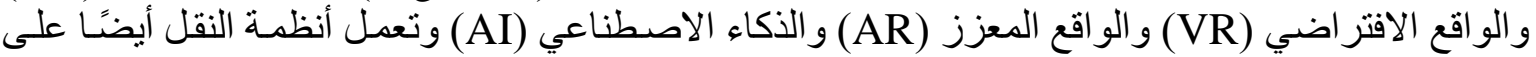

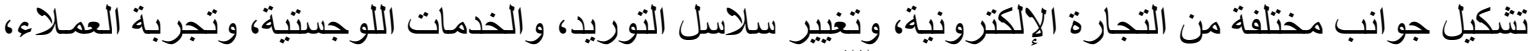

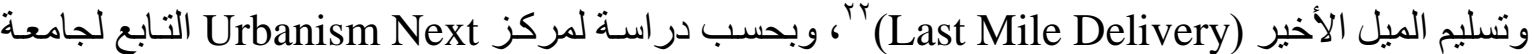

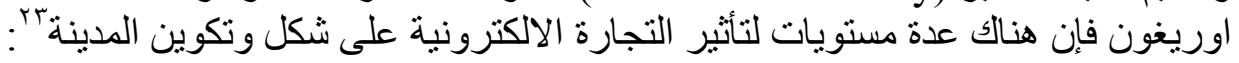

First order Impact المستوى الأول من التنأثير:

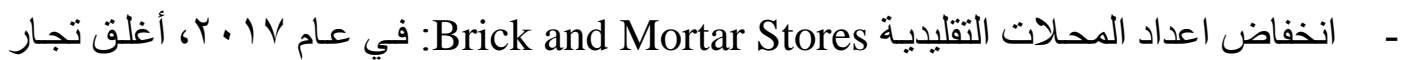

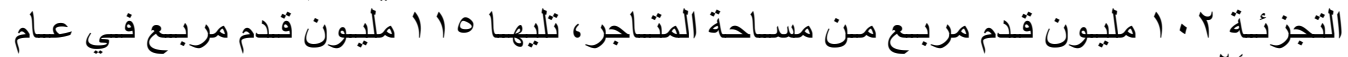
$r \varepsilon, 11$

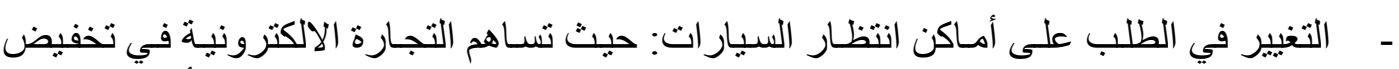
اعداد الرحالات من و الى المر اكز التجاريـة مما يسـاهم في انخفاض الطلب على أمـاكن انتظـار

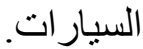

- التغير في توصيل السلع و الوجبات: تسعى الثركات المعتمدة على الأنشطة التجاريـة الالكترونيـة

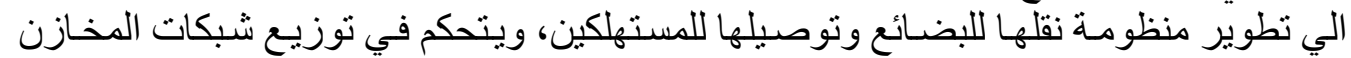

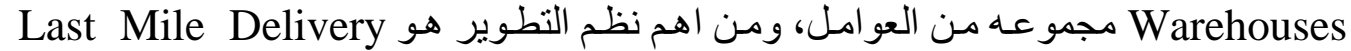

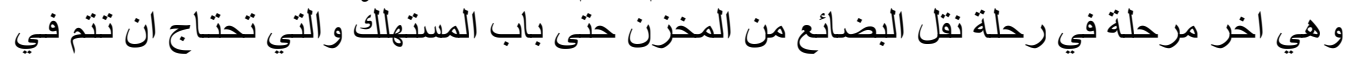
اقل مدى زمني.

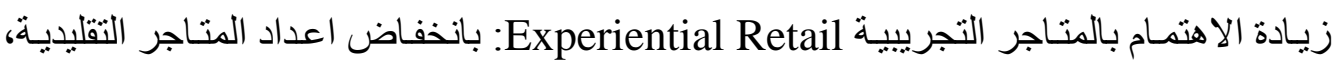

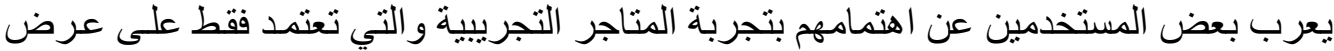
البضائع وشر ائها من المتاجر الالكترونية، والتي تعد أصغر في الحجم من نظيرتها التقليدية.

المستوى الثاني من التأثير Second order Impact:

- التغير في معدل التوظيف Employment: على الرغم مـن المخـاوف التي تحملهـا التجـارة

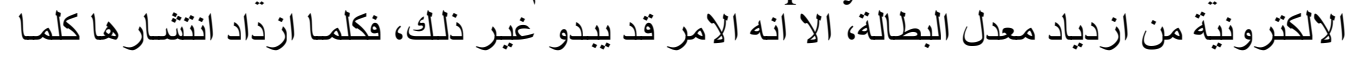

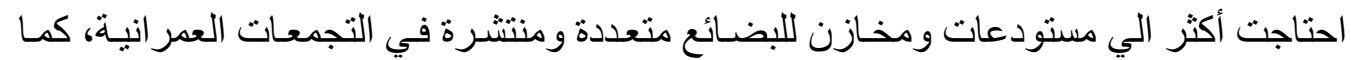

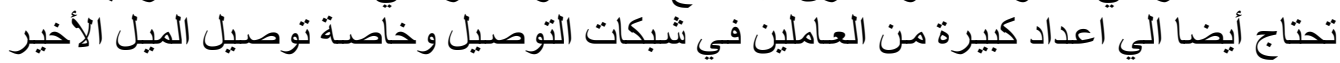

.Last Mile Delivery

- التغير في معدلات المناطق السكنية والأماكن الترفيهية: تساهم التجارة الالكترونية بشكل إيجابي

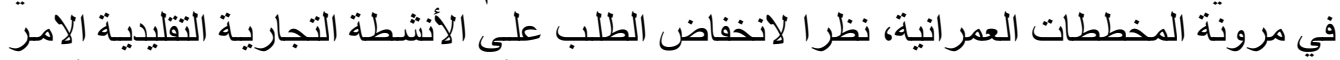

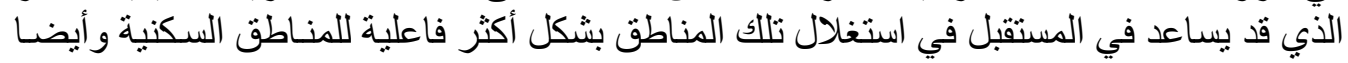

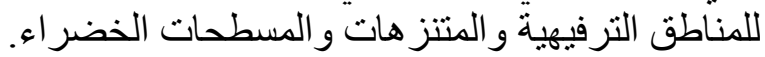

\footnotetext{
${ }^{22}$ Reddy, N., "The future of e-commerce", USA, 2018.

${ }^{23}$ Urbanism next center, "Multilevel Impacts of Emerging Technologies on City Form and Development", University of Oregon, 2020.

${ }^{24}$ Peterson, $\mathrm{H}$, "More than 8,000 stores are closing in 2019 as the retail apocalypse", Business Insider website, 2019.
} 


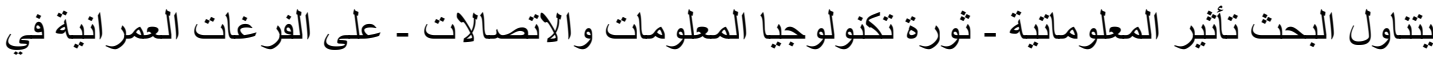

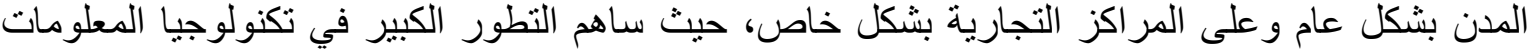

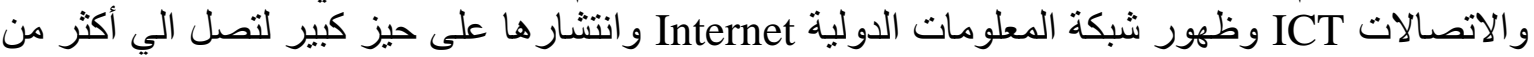

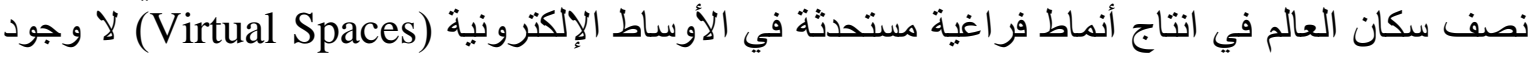

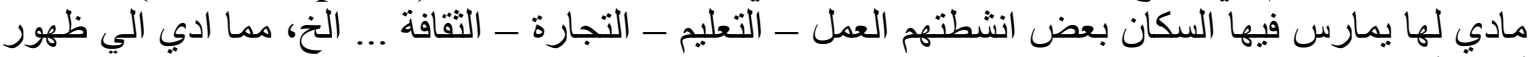
أنماط أخرى من المدن الذكية و الالكترونية و المعلو ماتية.

Informatics وتمثل المعلوماتبة التأثبر الأهم على تلك التجمعات العمرانية في تسخير تطبيقاتها Applications

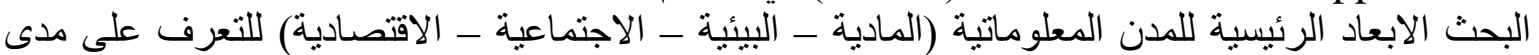

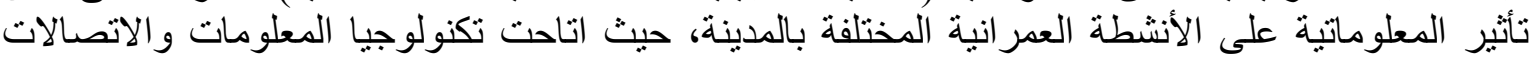

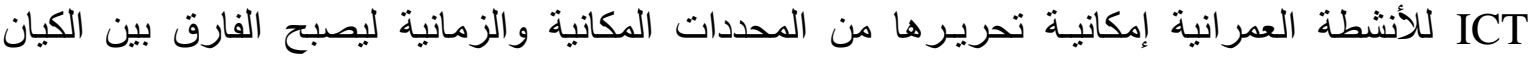

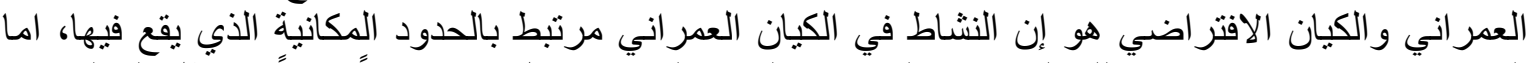

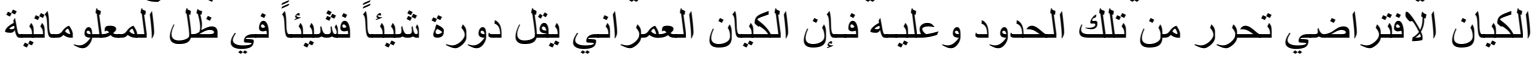

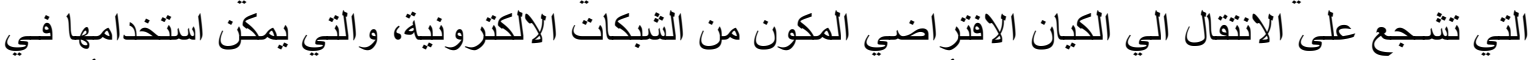

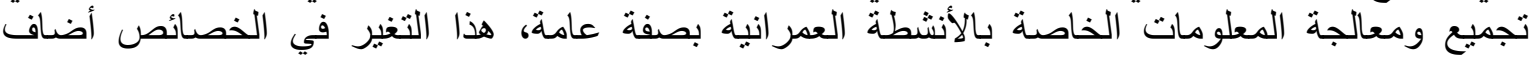
للأنشطة المعلوماتية مجمو عة من السمات الجديدة:

التحرر من القيود الزمانية و المكانية للأنشـطة اعتمـادا على الاتصـال الإلكتروني بين هذه مقدم ومستقبل

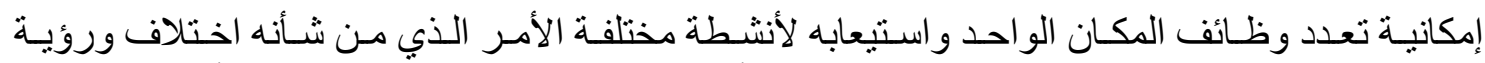

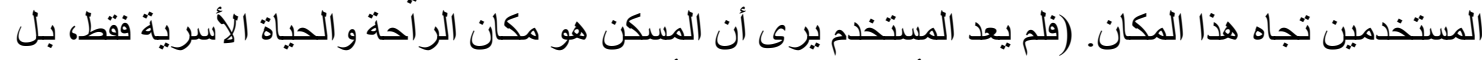

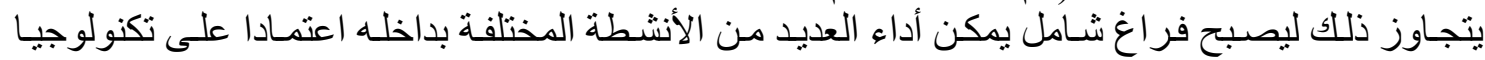
المعلومات و الاتصالات).

تأثثر مو اقع التواصل على الهيكل الاجتمـاعي للمدينـة، حيـث تتغير الانشطة الاجتماعيـة بين المستخدمين كما تأثر التكوين الاجتماعي لهم.

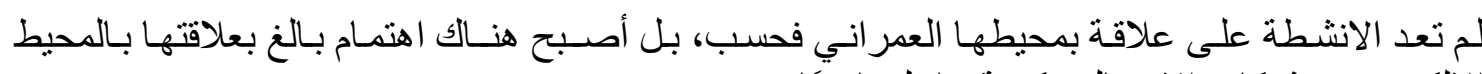
الإلكتروني وشبكات الاتصال وكيفية تفاعلهما معًا.

انعكاس سهولة تداول المعلومات ومعالجتها كما وكيفًا على فاعلية أداء الأنشطة الحياتية المختلة.

أصبحت تتيح الأوساط الافتر اضية للأنشطة عدد لانهائي من الحلول يتم توظيفها وفقًا للظروف الملائمة.

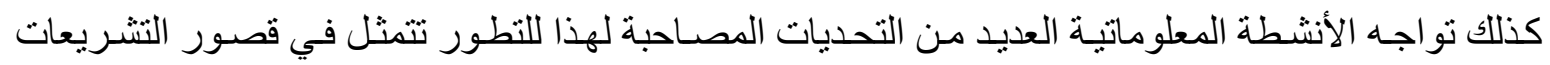

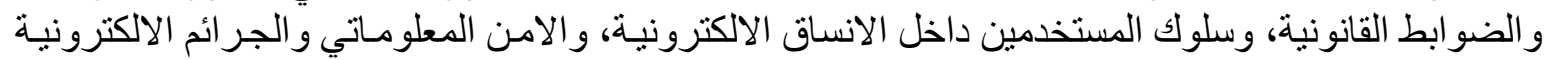
وجر ائم الأموال و التجسس الالكثروني.

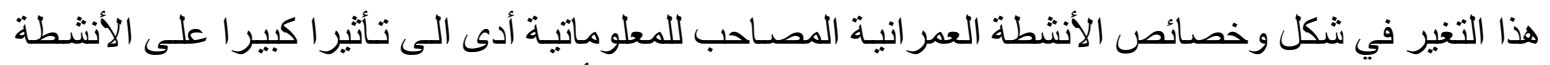

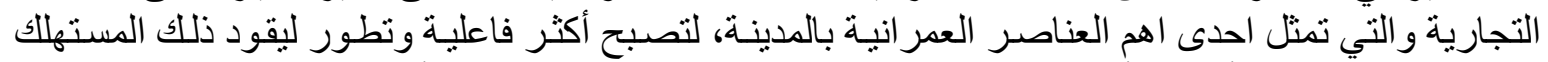

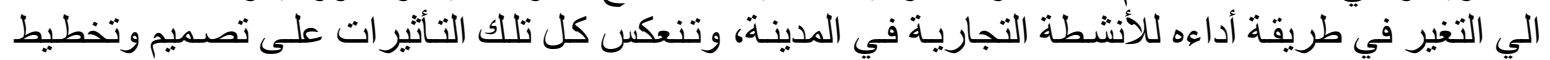

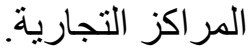

أولا التغيير في المكونات الأساسية لعناصر المر اكز التجارية حيث ان بالاعتماد المتز ايد على المعلوماتية

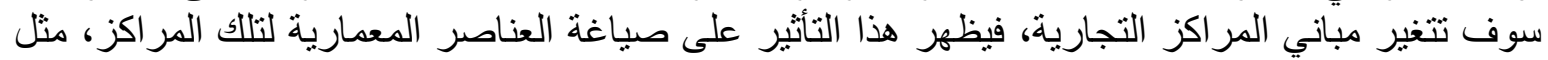

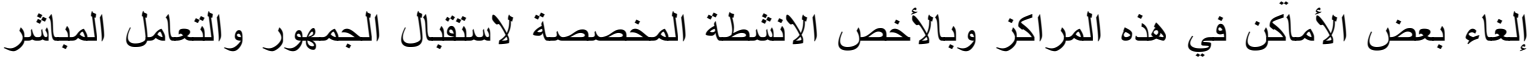


معهم، وسيترتب على ذلك تخصيص مساحات صغيرة لبناء هذه المباني بنسبة كبيرة، قد يمكن استخدامها مستقبلا في معالجة مشناكل عمر انية أخرى.

ثانيا التغيير في المكونات التشكيلية للمر اكز التجارية من خلال التغير في خصائص الأنشطة التجارية التقليدية

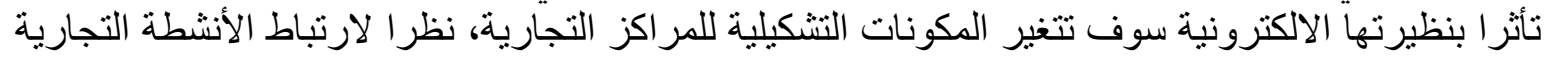

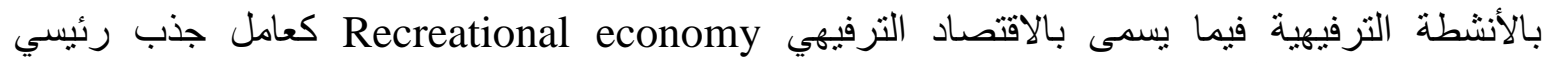
للمستهلكين للتردد على المر اكز التجارية.

ثالثا التغيير في نمط تخطيط وتوزيع المراكز التجارية نظرا للإمكانيات الكبيرة التي تتيحها تكنولوجيا

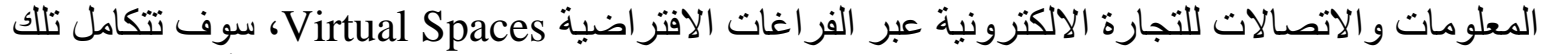
الفراغات مع الفراغات العمر انية لتكون نمط جديد من المر اكز التهات التجارية يعتمد على التركيز أحيانا والانتشار

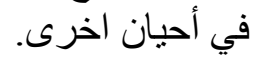

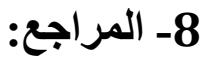

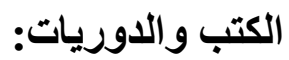

- Brotchie, J.,et al., "Cities in competition, productive and sustainable cities for the 21st Century", Longman Australia, 1995.

- Cailin Crowe, "Miami Pilots E-cargo Bikes to Reduce Congestion, Pollution," Smart Cities Dive, May 18,2020.

- City of Boston, "City releases RFI for electric cargo bikes as a delivery solution," July 20, 2020.

- George Gilder, Forbes ASAP, February 27, 1995.

- J. Peterson, "Information Methods for Design and Construction", New York, $198 \cdot$.

- Jess Gaspar and Edward L. Glaeser, Information Technology and the Future of Cities, Harvard Institute of Economic Research, Harvard University, April 1996.

- Laura Kusisto, "Amazon and Big Apartment Landlords Strike Deals on Package Delivery," Wall Street, Journal, October 17, 2017.

- Mayor de Blasio Announces Commercial Cargo Bike Program to Reduce Delivery Congestion," New York City, Department of Transportation, December 4, 2019.

- Merlyna Lim, "From Walking City to Telematic Metropolis: Changing Urban Form in Bandung, Indonesia". Critical Reflections on Cities in Southeast Asia. Brill Publisher and Times Academic Press, 2002.

- Moss \& Townsend, "Why Cities will thrive in the information age" Cities in the 21st century, the urban land institute, USA, 2000.

- Nigel Thrift, "New Urban Eras and Old Technological Fears: Reconfiguring the Goodwill of Electronic Things" Urban Studies, Vol. 33, No. 8, 1996.

- Peter Gordon and Harry W. Richardson, "Are Compact Cities a Desirable Planning Goal?" Journal of the American Planning Association, Vol. 63, No.1, winter, 1997.

- Peterson, H, "More than 8,000 stores are closing in 2019 as the retail apocalypse", Business Insider website, 2019. 
- Polatoglu, V.N., "Strategies that work - the case of an e-retailer in an emerging market", International Journal of Emerging Markets,2007.

- Reddy, N., "The future of e-commerce", USA, 2018.

- Riewoldt, O., Intelligent Spaces, Architecture for The Information Age, Laurence king, Hong Kong, 1997.

- Robin Wigglesworth, "Will the Death of U.S. Retail be the Next Big Short?," Financial Times, July 16, 2017.

- Ronald Abler, "What Makes Cities Important,” Bell Telephone Magazine, MarchApril 1970.

- UNCTAD, PRESS, PR,3,2015.

- United Nations conference on trade and development, "COID-19 and ECommerce impact on businesses and policy responses",2020.

- United Nations conference on trade and development, "ICT Policy review: National ECommerce strategy for Egypt",2017.

- Urbanism next center, "Multilevel Impacts of Emerging Technologies on City Form and Development", University of Oregon, 2020.

- Wheeler, J. et al, "Cities in the Telecommunication Age", Routledge, London, 2000.

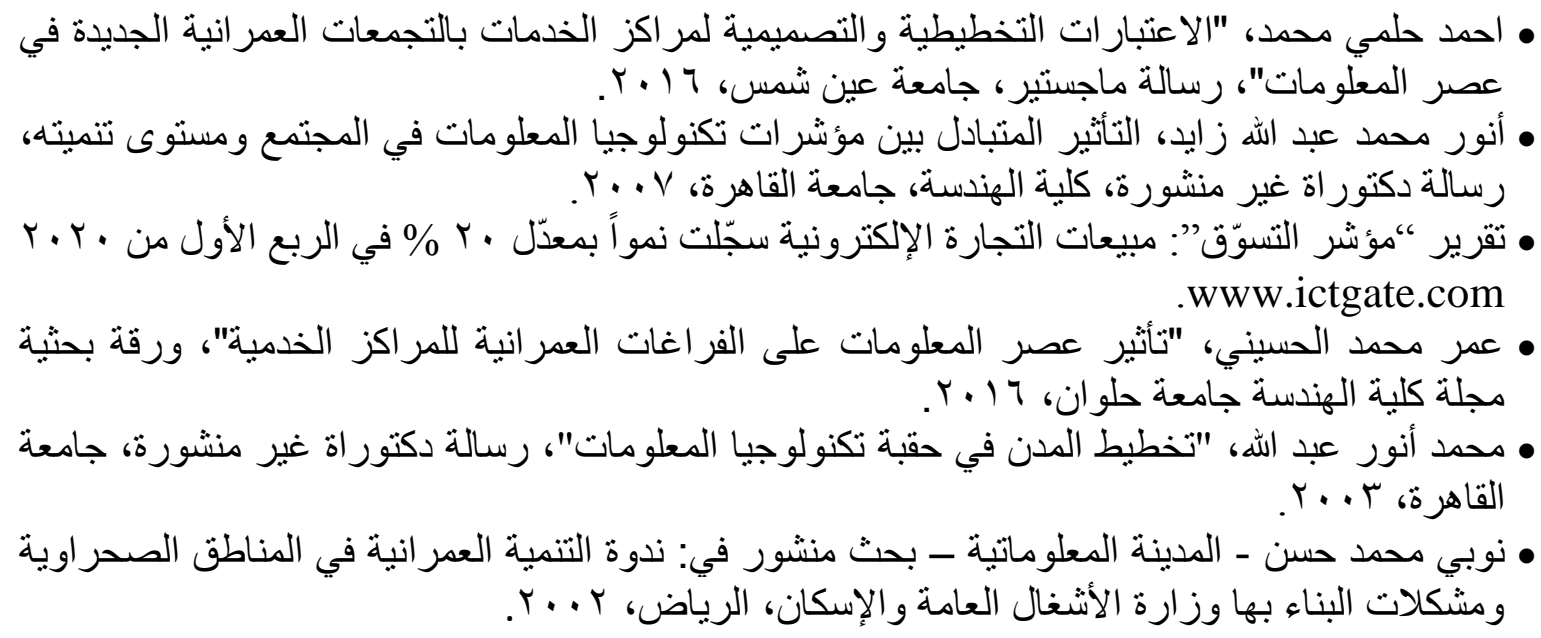

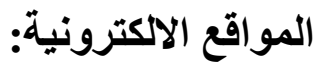

- Commercial Website - AVINTEGRATION - https://av-news.co.za/, 2021.

- Commercial Website - Forbes - https://www.forbes.com/the-worlds-mostvaluable-brands/\#538e5012119c - 2021.

- Commercial Website - Game Radar - https://www.gamesradar.com/, 2021.

- Commercial Website - http://www.amazon.com/, 2021.

- Commercial Website - Oberlo - https://www.oberlo.com/statistics/globalecommerce-sales , 2021.

- Commercial Website - Statista - https://www.statista.com//, 2021.

- Commercial Website - Tectales - where the future of healthcare begins https://tectales.com/, 2021.

- Commercial Website - Toptal - https://www.toptal.com/, 2021.

- Organization Website - Heritage in Motion - https://heritageinmotion.eu/, 2021. 
Ghada farouk hassan / et al/ Engineering Research Journal 171(september 2021/ AA18- AA34

- Organization Website - $\quad$ World Bank https://data.worldbank.org/indicator/it.net.user.zs, 2021. 